\title{
Latitudinal patterns of phenology and age-specific thermal performance across six Coenagrion damselfly species
}

\author{
Viktor Nilsson-Örtman, ${ }^{1,4}$ Robby Stoks, ${ }^{2}$ Marjan De Block, ${ }^{2}$ and Frank Johansson ${ }^{1,3}$ \\ ${ }^{1}$ Department of Ecology and Environmental Science, Umeå University, SE-90187 Umeå, Sweden \\ ${ }^{2}$ Laboratory of Aquatic Ecology and Evolutionary Biology, University of Leuven, Charles Deberiotstraat 32, \\ BE-3000 Leuven, Belgium \\ ${ }^{3}$ Department of Ecology and Genetics, Uppsala University, SE-75236 Uppsala, Sweden
}

\begin{abstract}
Using a combination of computer simulations and laboratory experiments we test if the thermal sensitivity of growth rates change during ontogeny in damselfly larvae and if these changes can be predicted based on the natural progression of average temperature or thermal variability in the field. The laboratory experiment included replicated species from Southern, Central, and Northern Europe. Although annual fluctuations in temperature represent a key characteristic of temperate environments, few studies of thermal performance have considered the ecological importance of the studied traits within a seasonal context. Instead, thermal performance is assumed to remain constant throughout ontogeny and to reflect selection acting over the whole life cycle. The laboratory experiment revealed considerable variation among species in the strength and direction of ontogenetic performance shifts. In four species from Southern and Central Europe, reaction norms were steepest during early ontogeny, becoming less steep during later ontogenetic stages (indicative of lowtemperature acclimation). In one Northern European species, the slope of reaction norms did not change during ontogeny. In the other North European species, reaction norms became steeper during ontogeny (indicative of high-temperature acclimation). We had expected highlatitude species to show strong low-temperature acclimation responses, because they have a short flight season and inhabit a strongly seasonal environment. Instead, we found the reversed pattern: Low-latitude species displayed strong low-temperature acclimation responses, and high-latitude species displayed weak, or even reversed, acclimation responses to low temperatures. These findings suggest that low-temperature acclimation may be less beneficial and possibly more costly in habitats with rapid seasonal transitions in average temperature. We conclude that thermal performance traits are more dynamic than typically assumed and caution against using results from single ontogenetic stages to predict species' responses to changing environmental conditions.
\end{abstract}

Key words: acclimation; acclimatization; climate change; developmental plasticity; growth rate; life history; optimality theory; reaction norm; thermal sensitivity; thermal variability.

\section{INTRODUCTION}

Phenology (the timing and duration of seasonal phenomena) and the thermal sensitivity of physiological rate traits have emerged as two central concepts for understanding and predicting biological responses to climate change (Parmesan 2006), yet they are typically studied in isolation (Forrest and Miller-Rushing 2010, but see John-Alder et al. 1988 and Berger et al. 2011). This obscures the fact that phenology affects virtually all biological processes, including physiology (Forrest and Miller-Rushing 2010) and that thermal physiology, in turn, acts as a major determinant of phenology (Bentz et al. 1991, Régnière and Logan 2003). It may therefore be

Manuscript received 10 August 2012; revised 14 January 2013; accepted 12 March 2013. Corresponding Editor: N. J. Sanders.

${ }^{4}$ Present address: Ecology and Evolutionary Biology, 25 Willcocks Street, Toronto, Ontario M5S 3B2 Canada.

E-mail: viktor.j.nilsson@gmail.com more appropriate to view a species' phenology, ecology, and stage-specific thermal physiology as a suite of traits connected through life history trade-offs, where a change in one is correlated with, and sometimes constrained, by the others (Angilletta et al. 2006). Several studies have demonstrated how the phenological timing of important life history events such as reproduction and hibernation can evolve rapidly (Feder et al. 1993, Bradshaw and Holzapfel 2001, Nussey et al. 2005), but the magnitude of these changes is typically at the scale of days to weeks. More pronounced changes in phenology, e.g., a shift from being active in spring to being active in fall, appears to be rare evolutionary events. This is reflected in that the seasonal timing of reproduction displays a high level of phylogenetic conservatism in diverse groups of plants and animals (Kochmer and Handel 1986, Wolda 1988, Davis et al. 2010). That major phenological changes are constrained despite the potential for rapid microevolutionary changes suggest that phenological strategies involves a great 
number of interacting traits that must evolve in concert. Identifying the trade-offs that connect phenological and physiological traits will be an important step towards unifying them within the framework of life history theory (Zera and Harshman 2001, Roff 2002, Forrest and Miller-Rushing 2010). Insects are ideal subjects for studying these questions, as they have evolved a multitude of seasonal strategies, driven largely, but not solely, by temperature, with seasonal variation in precipitation, photoperiod, food availability, competition, parasitism, and predation also being important factors (Wolda 1988).

Thermal performance curves (TPCs) are reaction norms that describe how performance traits vary with temperature (Via and Lande 1985, Kingsolver and Gomulkiewicz 2003). These will be an essential component in the development of a life history framework that combines phenological and physiological traits. However, theoretical models exploring how TPCs evolve have generally not considered performance within a phenological context. Instead, they have assumed that TPCs remain constant throughout an individual's lifetime, focusing on specialist-generalist trade-offs between the width and height of reaction norms (Angilletta et al. 2003). This has inspired the notion that species can be separated into thermal generalists (Fig. 1A) and specialists (Fig. 1D; Lynch and Gabriel 1987, Gilchrist 1995, Asbury and Angilletta 2010). From physiological studies, however, it has become clear that TPCs can display considerable developmental plasticity during ontogeny (Prosser 1991, Huey and Berrigan 1996, Dreyer et al. 2001). Ontogenetic changes affecting the shape of TPCs can broadly be separated into reversible acclimation (Fig. 1B) and developmental acclimation responses (Fig. 1C; Angilletta 2009). In the first, physiological changes are represented by gradual, reversible changes in response to diurnal or seasonal changes in temperature. In the second, physiological changes are irreversible and occur at certain points in time, determined either genetically or by environmental cues (Bowler and Terblanche 2008, Angilletta 2009). In practice, it is difficult to distinguish between reversible and irreversible acclimation responses (Terblanche and Chown 2006, Angilletta 2009). For simplicity, we will use the terms acclimation and developmental plasticity of TPCs broadly, to indicate ontogenetic changes affecting the shape of TPCs.

Despite the well-documented existence of developmental plasticity of thermal performance, empirical studies typically estimate TPCs for a single ontogenetic stage following temperature exposures that vary widely in duration. With regards to growth rates, the performance trait studied here, TPCs have been quantified for a range of ontogenetic stages, sizes, and ages, with exposure times ranging from hours (Kingsolver et al. 2004) to weeks (Van Doorslaer and Stoks 2005) or months (Demont et al. 2008). Estimated this way, TPCs include an unknown component of acclimation and may only be representative of the studied developmental stage (Schulte et al. 2011). The extent to which the results from these studies are representative of organismal behavior across a wider range of thermal conditions remains an open question.

Developmental plasticity of TPCs, especially variation in the strength of reversible acclimation responses, are widely believed to be important for predicting the outcome of climate change (Stillman 2003, Gunderson et al. 2010, Somero 2010). Yet, few predictive models on climate change account for acclimation (Thomas et al. 2004, Kattge and Knorr 2007, Deutsch et al. 2008). This largely reflects a limited understanding of the ecological and evolutionary factors that underlie variation in acclimation responses (Parry 1978, Wilson and Franklin 2002, Atkin et al. 2005, Davidson and Janssens 2006, Gunderson et al. 2010). Although theoretical work has suggested that the ability to acclimate should be strongest in organisms from variable environments, such as those found at high latitudes (Gabriel and Lynch 1992, Gabriel 1999), this prediction has not been generally supported by empirical evidence (Cunningham and Read 2002, Angilletta 2009, Cooper et al. 2010).

Instead, several studies have suggested that both the shape of TPCs and patterns of developmental plasticity of TPCs must be interpreted in relation to species' seasonal phenology. For example in fish, odonate larvae, and water striders, thermal optima of growth rates have been found to be higher in ontogenetic stages that are found during summer than in those that occur during the colder months (Spence et al. 1980, Schultz et al. 1996, van Doorslaer and Stoks 2005). Similarly, several species of trees and herbaceous plants display stronger acclimation responses of photosynthesis during the warmer months (Zhou et al. 2007, Gunderson et al. 2010, but see Dillaway and Kruger 2010). In fish that migrate from thermally heterogeneous intertidal waters to thermally stable but seasonally varying offshore waters, only offshore adults display acclimation responses of swimming speed (Temple 1998). In sticklebacks, acclimation of swimming speeds occur during the fall, but not in spring (Guderley et al. 2001). In frogs, acclimation of locomotion and muscle performance have been observed in aquatic, but not terrestrial stages (Wilson et al. 2000), and thermal optima have been found to vary in relation to the timing of reproduction (John-Alder et al. 1988). The mechanisms of developmental plasticity underlying these examples are likely to differ substantially. Nevertheless, they clearly illustrate the importance of studying thermal performance in relation to species' seasonal phenology.

Here, we used six European species of damselflies in the genus Coenagrion to investigate whether the thermal sensitivity of larval growth rates changes during ontogeny, and if the strength and direction of these changes can be predicted based on how the thermal niche changes during ontogeny in the field. We quantified ontogenetic changes in thermal performance 


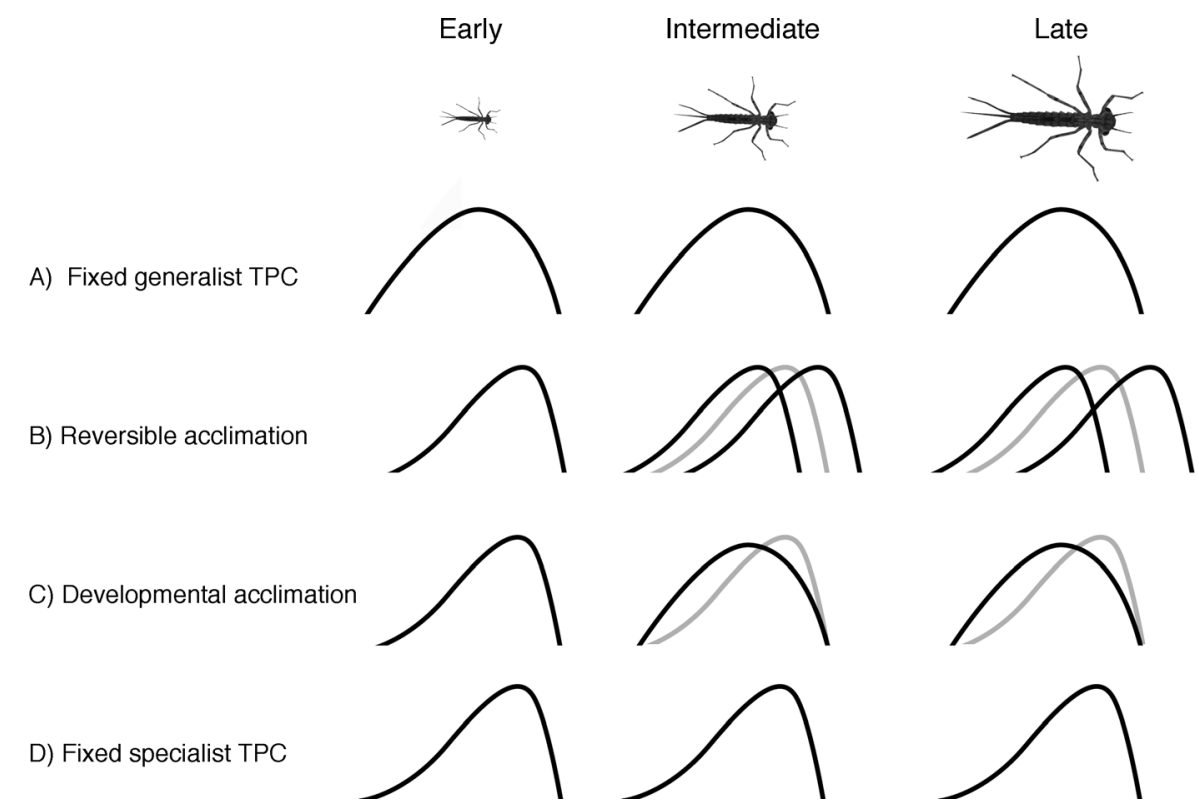

FIG. 1. Conceptual model of how thermal physiology may (A, D) remain unchanged or (B, C) change during ontogeny. Each row represents one of four strategies discussed in the Introduction. Curves drawn with solid black lines represent the short-term performance during early, intermediate, and late ontogeny under that strategy. Solid gray lines in the central and right column reiterate the thermal performance curves (TPCs) during early ontogeny for ease of interpretation. (A) A fixed generalist will display the same, broad, TPCs throughout ontogeny. (B) If ontogenetic shifts occur through reversible acclimation, the shape of short-term TPCs remains unaltered, but the location of the thermal optima will shift upward or downward depending on the temperatures an individual experience (shown here as a divergence into multiple TPCs that retain the same shape). (C) If ontogenetic shifts occur through developmental acclimation, the shape of short-term TPCs may differ during early and later stages. (D) A fixed specialist will show the same, steep, and narrow, TPCs throughout ontogeny. Note that for the two strategies involving acclimation (panels B and C), combinations including other TPC shapes are also possible.

by rearing individuals at one of several temperatures and monitoring their growth at the age of 42, 84, and 126 days. After correcting for the size dependence of individual growth rates, we compared TPCs of growth rates during early (days 0-42), intermediate (days 4284 ), and late (days 84-126) ontogeny. It is important to note that we could not separate reversible acclimation (Fig. 1B) from developmental acclimation (Fig. 1C) using this approach. Instead, observed ontogenetic changes in TPCs will represent the joint outcome of both processes.

To compare these data with information about how the thermal niche of these species changes in nature, we developed a computer model that allowed us to trace the thermal environment experienced by individual larvae. The model relies on modeled water temperature data and field data relating to the phenology of reproduction in each species. We hypothesize that the long summer season at lower latitudes would allow southern species to reproduce during a greater part of the year, leading to reduced synchrony of larval hatching and, consequently, unpredictable thermal conditions during larval development (with individuals' hatching early or late in the season inhabiting very different thermal environments). High-latitude species on the other hand, were hypothesized to reproduce during a shorter period of time, leading to more synchronized hatching and, consequent- ly, more predictable larval growth conditions. Based on this, we predicted that southern species should be obligate thermal generalists (Fig. 1A) because of the unpredictable nature of their larval environment, whereas northern species should display strong ontogenetic shifts (switching from being thermal heat specialists during early ontogeny to performing better at lower temperatures during later stages; Fig. 1B) because larvae experience more predictable changes in the thermal niche during development in the field (due to the short period of reproduction). Central European species were predicted to be intermediate, displaying moderately strong ontogenetic shifts.

\section{Materials And Methods \\ Study species}

The six damselfly species included in this study all belong to the predominantly Palearctic genus Coenagrion and were chosen because they clearly differ in the latitudinal extent of their distribution ranges. Coenagrion mercuriale and C. scitulum occur in Southern Europe, $C$. puella and $C$. pulchellum have large ranges spanning much of Central Europe, and C. armatum and C. johanssoni are exclusively found in Northern Europe (Fig. 2). Coenagrion species mate in spring or summer, and females deposit their eggs into submerged, aquatic plants. Eggs hatch after two to three weeks. Larvae are 
A) C. johanssoni

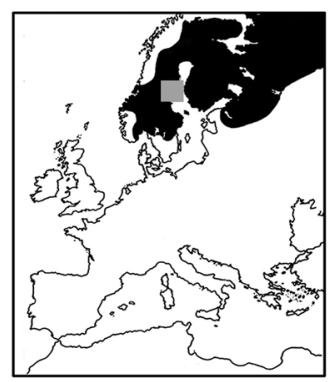

C) C. puella

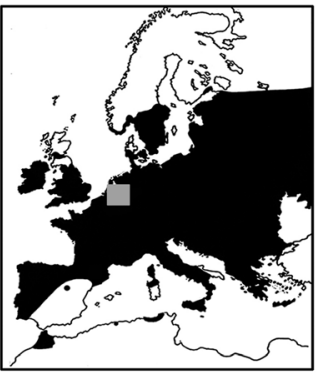

E) C. mercuriale

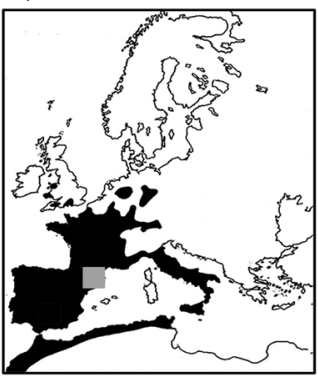

B) C. armatum

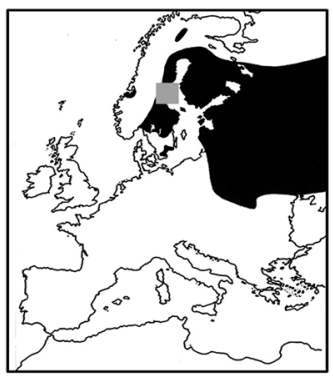

D) C. pulchellum

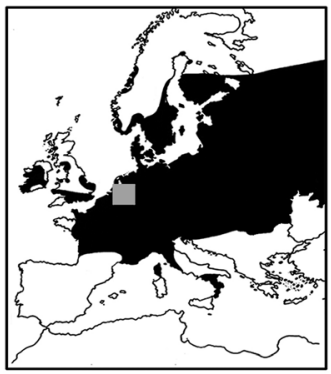

F) C. scitulum

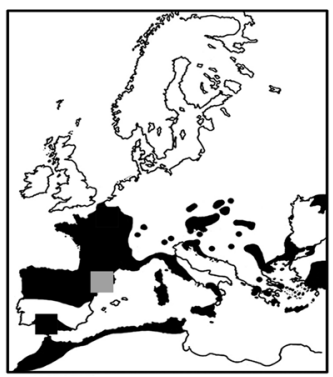

FIG. 2. Map showing the European distribution of the six studied Coenagrion species and the location of sampled sites. Each gray square represents the three nearby sub-populations that were sampled. Note differences in distribution pattern, with (A, B) two North European, (C, D) two Central European, and $(\mathrm{E}, \mathrm{F})$ two South European species being represented. Maps are based on Askew (2004) with permission from Apollo Books and updated with recent information.

generalist, aquatic predators feeding on smaller invertebrates. In fall, larvae enter a facultative diapause during which cold tolerance is increased and development is retarded or completely stopped (preventing premature emergence; Norling 1984, Corbet 1999). Diapause is initiated by both short photoperiods and low temperatures, with larvae entering diapause at temperatures below $8-10^{\circ} \mathrm{C}$ (Pritchard 1989). Odonates (dragonflies and damselflies) are well known to display plastic life histories, with gradually longer generation lengths towards higher latitudes (Corbet et al. 2006). After overwintering, larvae may thus either develop directly into adults or remain in the larval stage for one or several more years. The northern species in this study require two years to finish larval development, whereas

central species are univoltine (Norling 1984, Corbet 1999). The life cycles of the southern species are poorly known, but they are presumably univoltine in most areas.

\section{Thermal variability of the larval habitat}

To understand the thermal environment inhabited by the studied species, we used the lake model FLake (Mironov 2008) to generate an 11-year time series with twice-daily surface water temperatures that are representative of the sites from where the studied species were sampled. Meteorological observations for the years 1998-2009 (at 12-h intervals; day and night) on solar radiation, air temperature, air humidity, wind speed, and cloud cover from the ECMWF Era-Interim data set (Simmons et al. 2007) were used as forcing data. The average lake depth was set at $1 \mathrm{~m}$ (these species are most abundant at sites with shallow water), and the water was assumed to be relatively turbid, with a visibility of $0.4 \mathrm{~m}$ (these species are most common in vegetation-rich environments where visibility is reduced due to high levels of dissolved organic matter). Sediment layers are important for the thermal characteristics of shallow water bodies, so we assumed that each lake had a $1 \mathrm{~m}$ deep, thermally active sediment layer. FLake works by creating a one-dimensional (vertical) representation of the lake, divided into regions representing the surface water layer (mixed), thermocline, bottom water layer, and bottom sediment layer. Depending on the environmental forcing data, the depth at which the thermocline is located change during the simulations. Note that, because the modeled lakes are so shallow, they are completely mixed during the greater part of the year so that our surface water temperature estimates reflects conditions over the whole 1-m water column. We discuss this further in the Discussion. Nilsson-Örtman et al. (2012) have demonstrated the validity of this approach, compared to measurements from real European lakes. Note, however, that here we model a shallower, more turbid lake than previously, leading to somewhat higher estimates of average and maximal temperatures. We are confident that this better matches the typical habitat of these species. Six different FLake runs were executed using meteorological data corresponding to each of the areas from where the six species were sampled.

\section{Modeling hatching dates}

To get data on the thermal environment that individuals experience during their aquatic larval stage we developed a computer model describing the seasonal distribution of egg laying and hatching across latitudes, which was used to generate realistic hatching dates of 1000 individuals of each species at the sampled sites. By coupling the generated hatching dates to the surface water temperature data from the lake model FLake, we could trace the environment experienced by larvae in nature. The model was parameterized with information on the start and end of the flight season, the seasonal 
distribution of reproduction and embryonic development time. Assuming a single peak of reproduction each year, we modeled the probability of egg laying on a given day of the year, $P(\mathrm{egg})$, as a four-parameter betadistribution bounded between the start and end of the flight season:

$$
P(\mathrm{egg})=s+B(\alpha, \beta)(e-s)+m
$$

where $s$ is the start of the flight season (in day of the year), $e$ is the end of the flight season, $m$ is the assumed constant time lag between emergence and the time when the first egg is laid, and $B(\alpha, \beta)$ is the beta distribution. The beta distribution is defined by its probability density function:

$$
f(x)=\frac{x^{\alpha-1}(1-x)^{\beta-1}}{\Gamma(\alpha) \Gamma(\beta) / \Gamma(\alpha+\beta)}
$$

where $\alpha$ and $\beta$ are shape parameters representing the rate of increase of reproductive activity in spring $(\alpha)$ and the rate of decrease in reproductive activity in fall $(\beta)$; $\Gamma(\cdot)$ is the gamma function. A beta distribution was chosen based on its computational simplicity, flexibility in describing non-normal patterns in egg laying and, importantly, that it is bounded between 0 and 1 , allowing for easy scaling to the length of the flight season.

Assuming a constant time lag for embryonic development, i.e., between egg laying and hatching of larvae, the hatching day of a random individual $i, h_{i}$, is given by the function

$$
h_{i}=s+B(\alpha, \beta)(e-s)+m+d
$$

where $d$ is the embryonic development time. Eq. 3 was used to randomly generate individual hatching dates.

Although observational data on the seasonal occurrence of these species tends to display only marginally higher population densities early in the season, there are several reasons to believe that the seasonal distribution of egg laying (Eq. 1) is more strongly right-skewed. First, the distribution of observations indicative of reproduction is more right-skewed than the overall distribution of records in the Nordic biodiversity gateways (Artportalen and Rapporteringssystem for småkryp; data available online). ${ }^{5,6}$ Secondly, late-flying individuals tend to be males, with female population size decreasing more rapidly (Van Noordwijk 1978). Thirdly, Lowe et al. (2009) found, in the most exhaustive study to date, that egg laying was strongly right-skewed in $C$. puella. This right-skewness is likely a general pattern in summer-active species, as it has been observed previously in diverse taxa, including plants, insects, and birds (Rabinowitz et al. 1981, Danks 2006, Laaksonen et al. 2006).

Based on this, the final egg-laying model (Eq. 1) was parameterized with $\alpha=3, \beta=8$, and $m=12$, yielding a

\footnotetext{
${ }^{5} \mathrm{http}: / /$ www.artportalen.se/bugs

${ }^{6}$ http://artsobservasjoner.no/smakryp
}

right-skewed distribution that provides a good fit to the data from Lowe et al. (2009). Fig. 3 shows the relationship between the distribution of egg laying as modeled using Eq. 1 (solid gray line) compared to Lowe et al.'s (2009) field data (gray vertical bars). A detailed description of how the start and end of the flight season ( $s$ and $e$ in Eq. 1; solid gray arrowheads in Fig. 3) was estimated for each species follows in the next section. In the final larval hatching model (Eq. 3), the embryonic time lag $d$ was set at 25 days. In reality, embryonic development time in these species is temperaturedependent and follows a power-function (Waringer and Humpesch 1984, van Doorslaer and Stoks 2005), but within a realistic range of water temperatures, between $18^{\circ} \mathrm{C}$ and $25^{\circ} \mathrm{C}$, difference are relatively small, ranging from 20 to 30 days.

\section{Adult phenology}

In order to establish when the flight season of each species starts and ends in the sampled areas, we performed an exhaustive literature search for information on the phenology of Coenagrion spp. across the Western Palearctic. This resulted in a database containing 165 regional, species-level phenological records of start and end dates (Appendix B: Table B1), with 107 of these records relating to the six species studied here. For each species, we fitted two separate ANOVAs, one describing the latitudinal trend of the start, $s$, and one of the end, $e$, of the flight season. For each model, the day of the start or end of the flight season was used as the continuous response variable, and the latitudinal position from where the phenological record originated was used as the predictor variable. Quadratic and cubic latitude terms were included to test for nonlinear latitudinal trends, but removed if found nonsignificant. The start date model of a given species was thus of the form

$$
s=i+j \text { latitude }+k \text { latitude }^{2}+l \text { latitude }^{3}
$$

with $i, j, k$, and $l$ being fitted, polynomial coefficients. We included the quality of each phenological record (based on an assessment of the data format and sample size; see Appendix B: Table B1) as weights when fitting the models. Latitudinal trends in the end date were modeled likewise. For each species, the two best-fitting ANOVAs describing its phenology were used to predict the start and end of the flight season at the sampled latitudes (e.g., inserting the latitude 57.5 into Eq. 4 with the fitted polynomial coefficients from the two $C$. puella models [cf. Fig. 4D] yields the predicted start and end dates at Lowe et al.'s [2009] site in southern England, used to draw Fig. 3). The same approach was used to assess latitudinal trends in phenology for the genus as a whole.

\section{Thermal niche shifts during ontogeny}

In order to describe quantitatively how the thermal niche changes during ontogeny, we used the model 


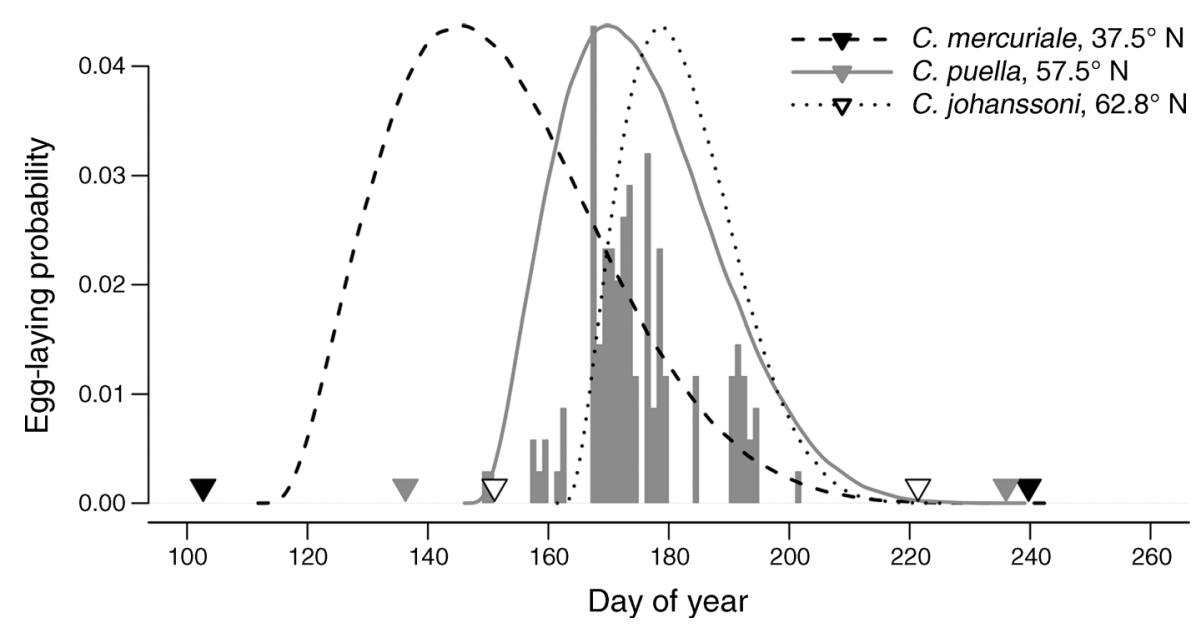

FIG. 3. Illustration of the model that was used to predict egg-laying dates across latitudes. Gray vertical bars show data on egg laying in Coenagrion puella in southern England $\left(57.5^{\circ} \mathrm{N}\right)$ from Lowe et al. (2009) that were used to parameterize the egg-laying model. Triangles along the $x$-axis denote the predicted start and end date of the flight season of each species, based on a literature survey of Coenagrion flight times across Europe. The solid, dashed, and dotted lines show the probability of egg laying at a given day of the year, predicted by the model (Eq. 1) for three different species. The model relies on the following: (1) start of the flight season, (2) end of the flight season, (3) rate of increase of reproductive activity in spring, (4) rate of decrease of reproductive activity in fall, and (5) a time lag between spring emergence and first reproduction. Thus, the solid gray line and gray vertical bars show the predicted and observed probabilities of egg laying at a given day of the year, respectively, for $C$. puella at $57.5^{\circ} \mathrm{N}$. Also shown are corresponding start and end dates and probabilities of egg laying for a southern (black triangles, dashed line) and northern (white triangles, dotted line) species. Note the right-skewed distribution of egg laying, the long reproductive period of the southern $C$. mercurial, and the late onset and short duration of the flight period of the northern $C$. johanssoni compared to the central and southern species.

described in Eq. 3 to generate the hatching date of 1000 individuals of each species. A birth year, within the range of 1998 to 2009, was randomly drawn for each individual. By coupling individual hatching dates to the FLake temperature data, we could trace the environmental conditions experienced by each individual during ontogeny. Thus, the temperatures an individual $i$ experiences during its first 126 days following hatching in environment $g$ was described by the vector

$$
\begin{gathered}
\mathbf{E}_{g, i}^{0-126}=\left(T_{g, h}^{0}, T_{g, h}^{12}, T_{g, h+1}^{0}, T_{g, h+1}^{12}, T_{g, h+2}^{0}, T_{g, h+2}^{12},\right. \\
\left.\ldots, T_{g, h+125}^{0}, T_{g, h+125}^{12}\right)
\end{gathered}
$$

where $h$ is the day of hatching (in day of the year), $T_{g, h}^{0}$ is the surface water temperature in environment $g$ at midnight on day $h$ (from the lake model FLake), and $T_{g, h}^{12} \mathrm{i}$ is the temperature at noon. We focused on changes in average temperature and in the amount of thermal variability during ontogeny. For each simulated individual we calculated the mean temperature and amount of thermal variability of temperature variation experienced during early, intermediate, and late ontogeny. This was defined as the mean and the median absolute deviation, MAD, of the vectors $\mathbf{E}_{g, i}^{0-42}, \mathbf{E}_{g, i}^{42-84}$, and $\mathbf{E}_{g, i}^{84-126}$, with notation as in Eq. 5. We used the sample MAD (defined as the median of the absolute residuals from the median) as the measure of thermal variability rather than the sample variance or standard deviation as MAD is robust to outliers and scale (Hampel et al. 1986). Mean $\pm 95 \%$ CIs of the mean and MAD of temperature variation were calculated using data from all 1000 individuals of each species. These measures were used to describe how the environment changes during ontogeny in each species, area, and age class. Note that because measurements were calculated for each individual separately, fluctuations in average temperature among years do not affect our estimates of thermal variability. The three age classes (days $0-42$, days $42-84$, and days 84-126) were found to correspond to, roughly, the age classes that occur during summer (mid-July to end of August), early autumn (end of August to early October), and autumn to early winter (early October to mid-November), and thus represent the majority of the conditions experienced from hatching to the onset of winter diapause.

In addition, we calculated the rate of change in the mean and MAD of temperature during ontogeny. Rates of change from early to intermediate ontogeny were calculated for each individual $i$ as

$$
\Delta \text { mean }=\frac{\operatorname{mean}\left(\mathbf{E}_{g, i}^{42-84}\right)-\operatorname{mean}\left(\mathbf{E}_{g, i}^{0-42}\right)}{42}
$$

and

$$
\Delta \mathrm{MAD}=\frac{\operatorname{MAD}\left(\mathbf{E}_{g, i}^{42-84}\right)-\operatorname{MAD}\left(\mathbf{E}_{g, i}^{0-42}\right)}{42}
$$

with mean $\left(\mathbf{E}_{g, i}^{0-42}\right)$ denoting the mean temperature during days 0 to 42 , as in Eq. 5. Rates of change from intermediate $\left(\mathbf{E}_{g, i}^{42-84}\right)$ to late $\left(\mathbf{E}_{g, i}^{84-126}\right)$ ontogeny were calculated similarly. Rates of change in mean and MAD 

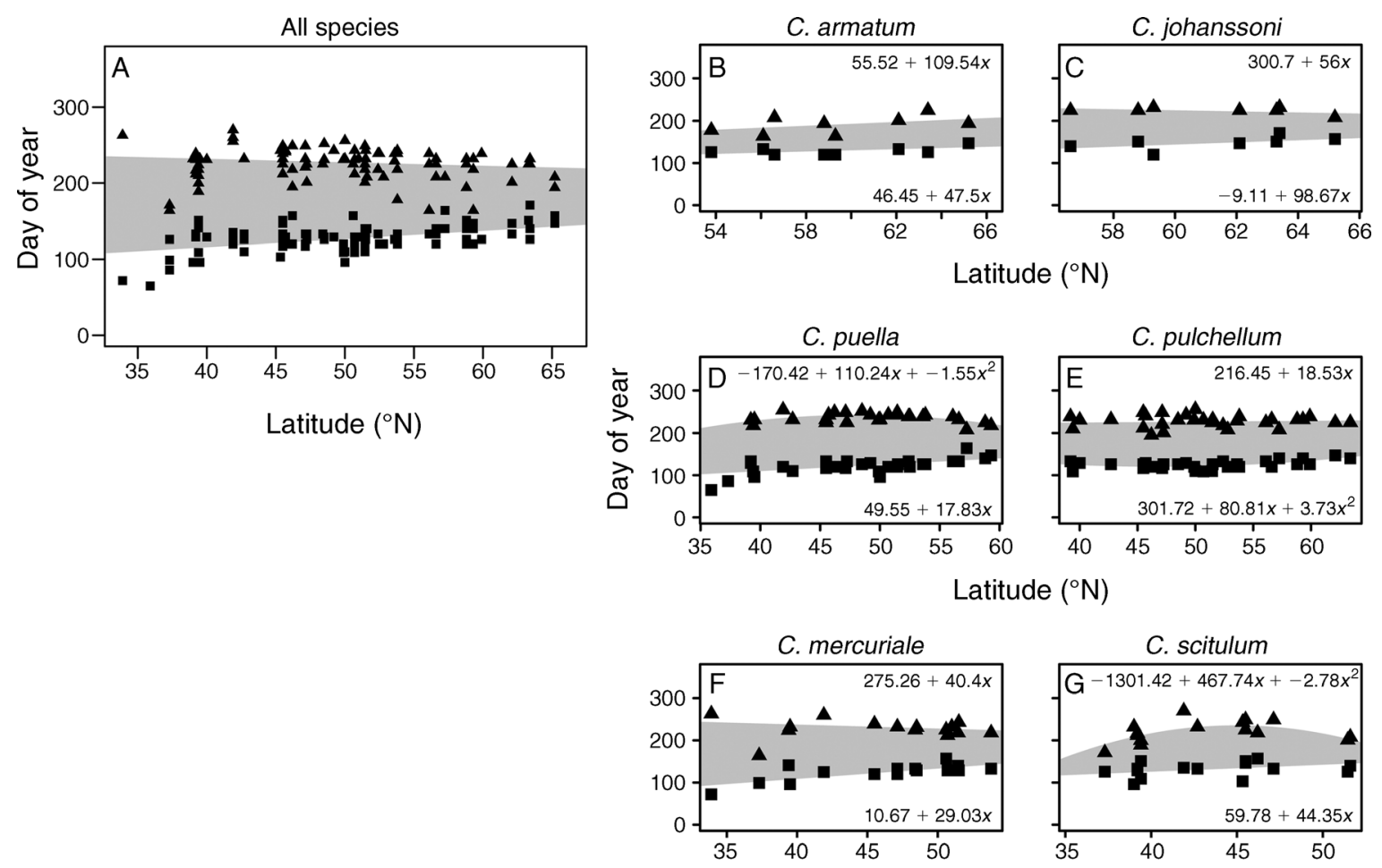

Latitude $\left({ }^{\circ} \mathrm{N}\right)$

FIG. 4. Flight periods across latitudes of European Coenagrion species. Shown are the latitudinal trends of (A) all 14 species and the six species included in the growth rate experiment, representing $(B, C)$ northern, $(D, E)$ central, and $(F, G)$ southern European distributions. Gray areas show the predicted length of the flight season at each latitude. Squares represent the start, and triangles the end of the flight period in each area from where we had data. The data come from the literature survey of phenological records across Europe. Note that the length of the flight season decreases with latitude (A) overall and in four species, the exceptions being $C$. armatum (having a more or less fixed length, but with a shift to a later flight season at higher latitudes) and $C$. scitulum (having the longest flight period at mid-latitudes). The best-fitting polynomial models describing the timing of the flight season are presented in each panel, showing the spring (bottom right) and fall (top right) phenology, respectively. These models were used to predict the start and end of the flight season of each species when fitting Eq. 3 .

were first calculated for each individual separately. Mean $\pm 95 \%$ CIs of changes in mean and MAD of temperature variation was then calculated using data from all 1000 individuals of each species.

\section{Ontogenetic shifts of thermal performance}

To assess whether the thermal sensitivity of growth rates changed during ontogeny, we conducted a common garden experiment where we traced the growth of individuals from hatching to 126 days of age in the laboratory. The details of the experimental conditions have been described previously (Nilsson-Örtman et al. 2012), and will be explained briefly here. Each of the studied species was sampled at sites close to the center of its range. Three separate populations of each species were sampled in order to minimize the influence of maternal and environmental effects. Only two central populations were sampled of $C$. johanssoni due to rainy and windy conditions during fieldwork. From each population, we reared the full-sib offspring from between 2 to 12 field-collected mated females (called "families") resulting in a total of 2105 individuals of 120 families. The fieldwork and rearing was divided over two laboratories and two years: C. armatum, C. johanssoni, and $C$. puella were collected and reared during 2008; $C$. mercuriale, C. pulchellum, and C. scitulum were collected and reared during 2009. A list of sampled populations is presented in Table 1. Mated females or their eggs were brought to the laboratory in Umeå, Sweden ( $C$. armatum, C.pulchellum, C. puella, and C. scitulum) or Leuven, Belgium (C. johanssoni and $C$. mercuriale). Immediately following hatching, 20 full-sib offspring from each female were transferred to individual $100-\mathrm{mL}$ rearing plastic cups and placed at random in one of four climate chambers (five individuals in each) set to give a water temperature of $16.3^{\circ} \mathrm{C}, 19.5^{\circ} \mathrm{C}, 21.5^{\circ} \mathrm{C}$, or $24.0^{\circ} \mathrm{C}$ $\left(24.0^{\circ} \mathrm{C}\right.$ added during the 2009 rearing) under a constant 14:10 light: dark (L:D) light regime. Larvae were fed 6 days a week on laboratory-reared brine shrimp, Artemia sp. The head width of each individual was measured at the age of $0,42,84$, and 126 days (called "measurement events"). For individuals lacking data from a single measurement event we imputed the missing data based on information from all individuals with complete 
TABLE 1. The geographic coordinates of the sampling sites used for this study.

\begin{tabular}{ll}
\hline \hline Species and locality & \multicolumn{1}{c}{ Coordinates } \\
\hline Coenagrion armatum & \\
Hamstasjön & $62^{\circ} 28^{\prime} 5^{\prime \prime} \mathrm{N}, 17^{\circ} 16^{\prime} 38^{\prime \prime} \mathrm{E}$ \\
Kråkholmen & $62^{\circ} 30^{\prime} 50^{\prime \prime} \mathrm{N}, 17^{\circ} 28^{\prime} 55^{\prime \prime} \mathrm{E}$ \\
Sticksjön & $62^{\circ} 24^{\prime} 51^{\prime \prime} \mathrm{N}, 17^{\circ} 16^{\prime} 18^{\prime \prime} \mathrm{E}$ \\
C. johanssoni & \\
Kustjärn & $62^{\circ} 9^{\prime} 2^{\prime \prime} \mathrm{N}, 17^{\circ} 29^{\prime} 59^{\prime \prime} \mathrm{E}$ \\
Rönnbottensviken & $62^{\circ} 8^{\prime} 25^{\prime \prime} \mathrm{N}, 17^{\circ} 29^{\prime} 24^{\prime \prime} \mathrm{E}$ \\
C. mercuriale & \\
Meder & $41^{\circ} 54^{\prime} 47^{\prime \prime} \mathrm{N}, 2^{\circ} 12^{\prime} 44^{\prime \prime} \mathrm{E}$ \\
Muntanyola & $41^{\circ} 52^{\prime} 60^{\prime \prime} \mathrm{N}, 2^{\circ} 10^{\prime} 11^{\prime \prime} \mathrm{E}$ \\
Mura & $41^{\circ} 41^{\prime} 56^{\prime \prime} \mathrm{N}, 1^{\circ} 58^{\prime} 35^{\prime \prime} \mathrm{E}$ \\
C. puella & \\
Arensberg & \\
Oud-Heverlee Zuid & $50^{\circ} 51^{\prime} 44^{\prime \prime} \mathrm{N}, 4^{\circ} 41^{\prime} 2^{\prime \prime} \mathrm{E}$ \\
Vinne & $50^{\circ} 50^{\prime} 22^{\prime \prime} \mathrm{N}, 4^{\circ} 39^{\prime} 20^{\prime \prime} \mathrm{E}$ \\
C. pulchellum & $50^{\circ} 50^{\prime} 3^{\prime \prime} \mathrm{N}, 5^{\circ} 7^{\prime} 6^{\prime \prime} \mathrm{E}$ \\
De Maten & \\
Mariehof & \\
Torfbroek & $50^{\circ} 56^{\prime} 53^{\prime \prime} \mathrm{N}, 5^{\circ} 26^{\prime} 47^{\prime \prime} \mathrm{E}$ \\
C. scitulum & $51^{\circ} 10^{\prime} 46^{\prime \prime} \mathrm{N}, 5^{\circ} 39^{\prime} 40^{\prime \prime} \mathrm{E}$ \\
Las Feixas & $50^{\circ} 55^{\prime} 36^{\prime \prime} \mathrm{N}, 4^{\circ} 32^{\prime} 24^{\prime \prime} \mathrm{E}$ \\
La Gavarresa & \\
Serratosa & $42^{\circ} 3^{\prime} 6^{\prime \prime} \mathrm{N}, 2^{\circ} 11^{\prime} 30^{\prime \prime} \mathrm{E}$ \\
\hline
\end{tabular}

records (see Nilsson-Örtman et al. 2012 for details). Individuals lacking data from two or more measurement events were excluded.

For each individual, we calculated three different measures of growth rates, reflecting growth between each of the three measurement events: days $0-42$, days 42-84, and days 84-126. We will refer to these three measurements as "early growth," "intermediate growth," and "late growth." Absolute growth rates (i.e., $\Delta \mathrm{hw} / \Delta t$ ) decrease with size, so we adjusted for differences in initial size at the start of each time interval by estimating a size-standardized measure of growth rate using the following formula:

$$
\mathrm{RGR}=\frac{\Delta \mathrm{hw}}{\Delta t}+b \mathrm{hw}_{t}
$$

where $\Delta$ hw is the change in head width (in $\mathrm{mm}$ ) between two consecutive measurement events ( $t$ and $t+1), \Delta t$ is the length of the time interval $(42 \mathrm{~d}), \mathrm{hw}_{t}$ is the head width at time $t$, and $b$ is an empirically determined coefficient describing the rate at which absolute growth rates decrease with size. This is equivalent to Ostrovsky's (1995) approach, except that we analyzed changes in length rather than mass. It is also identical to using size as a covariate in an ANCOVA of absolute growth rates (Nicieza and Álvarez 2009).

To estimate the size effect, $b$, we first modeled individual head widths of each species as a third-degree polynomial function of time. Next, we fitted a regression of how the slope of the fitted models decreased with size and used the slope of this relationship to estimate $b$ for each species (Appendix A: Fig. A3; Ostrovsky 1995). We expected that the fastest growing families of each species (those reared at the highest temperature) would be most appropriate to estimate the size effect, as the asymptotic growth trajectories of these families would more closely approximate the rate-limiting effect of size on growth than the more linear trajectories of slower growing families. C. johanssoni grew so slowly that it never reached the asymptotic phase during the experiment even at the highest temperature (Appendix A: Fig. A4) so the estimated value of $b$ for that species is a poor descriptor of the size effect (this likely only reflects low growth rates and not that growth is size independent in this species). In the other species, $b$ ranged from 0.015 and $0.022 \mathrm{~mm} /$ day for fast-growing families (Appendix A), with an average value of 0.019 . To ensure that the subsequent analyses were not affected by the value used for $b$, we recalculated RGRs using Eq. 8 using both common and species-specific values of $b$ (based on fastgrowing families; see Appendix A). This did not alter the outcome of subsequent analyses. In the final analysis we used $b=0.019$ to fit Eq. 8 for all species. It is important to note that the procedure for calculating size-corrected relative growth rates (Eq. 8) will lead to less precision when estimating growth rates during late growth stages in initially fast-growing phenotypes. Since these will have attained a greater size towards the end of the experiment, the size-correcting right-hand part of Eq. 8 will be large relative to the rate of absolute size growth. Note, however, that $C$. pulchellum showed a relative reduction in RGRs at $24^{\circ} \mathrm{C}$ during later growth phases. We are therefore confident that the size-correcting procedure is not related to the overall differences in slope or curvature of age-specific TPCs (Fig. 5). Note, however, that the exact estimates of significance levels of curvature parameters for single species (Appendix C: Table $\mathrm{C} 1$ ) should be interpreted with some caution.

Linear mixed-effect models (LMEs) were used to test if TPCs of RGRs differed depending on during what time interval growth rates were estimated. The three separate RGR estimates of each individual (representing early, intermediate, and late growth) were used as the response variable. The effects of temperature, species, and time period was included as fixed effects, together with the quadratic temperature term (to test for nonlinear relationships). Interactions of these factors up to the third order was included (e.g., species $\times$ time period $\times$ temperature). Population (nested in species), family (nested in population), and individual (nested in family) were included as random factors. Additionally, we compared the fit of this model to a set of models that ignored the nested structure of the data, but instead included time period grouped by subject (individual) as random effects and different within-subject errors correlation matrices. As the inclusion of correlated error structure did not improve model fit, the results from the model without correlated errors and with nested random effects are presented. 
Coenagrion johanssoni

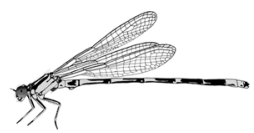

Coenagrion armatum

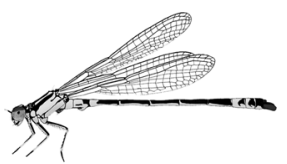

Coenagrion puella

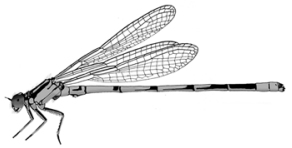

Coenagrion pulchellum
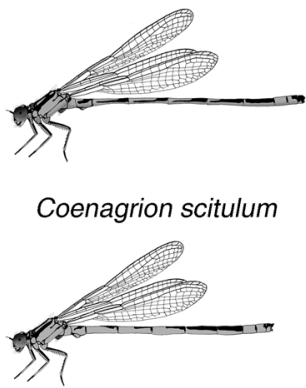

Coenagrion mercuriale

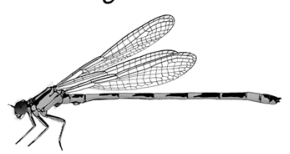

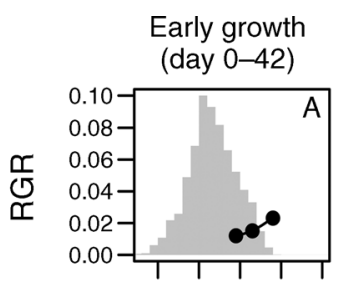

Intermediate growth (day 42-84)
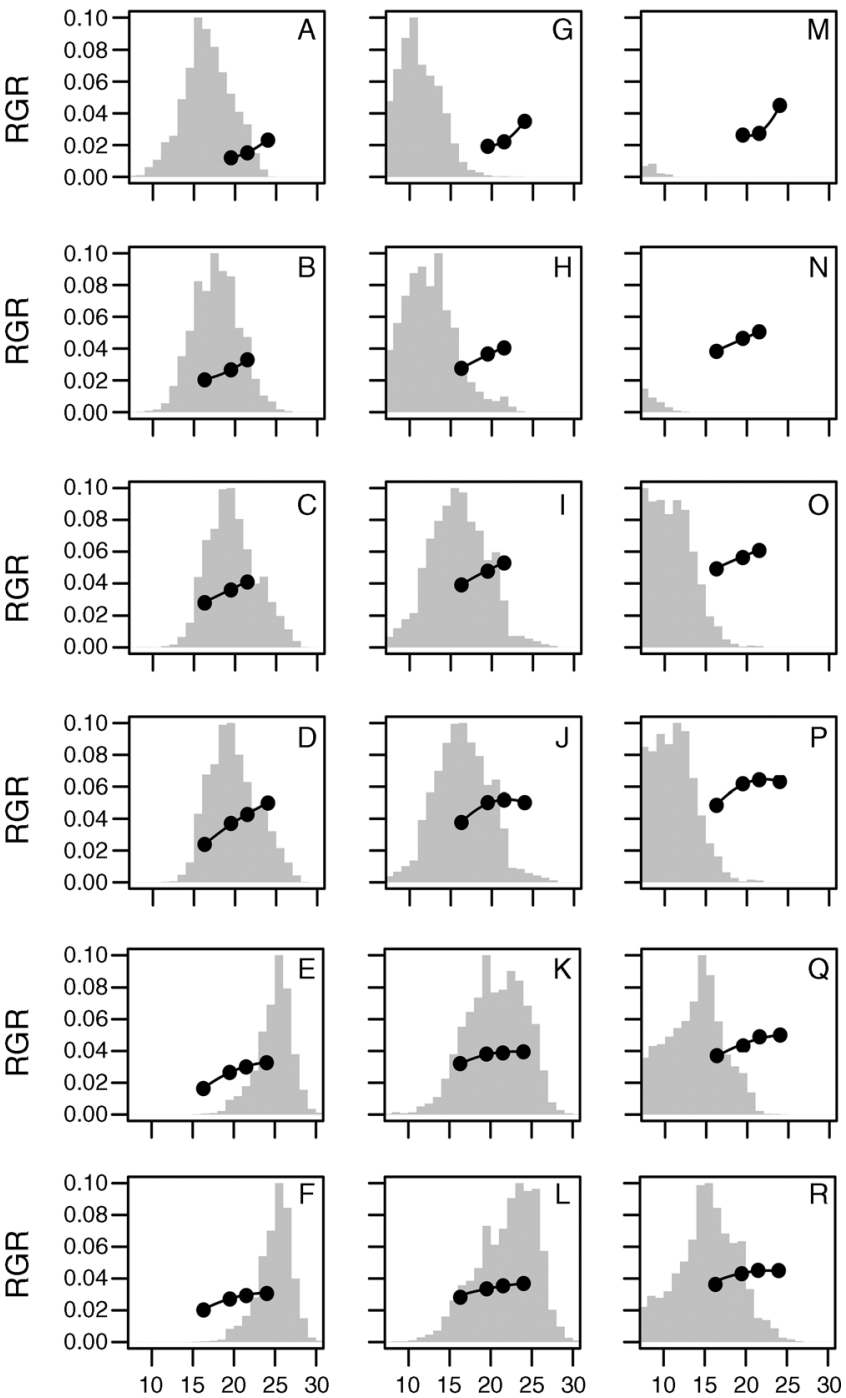

Temperature $\left({ }^{\circ} \mathrm{C}\right)$

FIG. 5. Ontogenetic shifts in the shape of TPCs of relative growth rates (RGR; black lines) in relation to the distribution of temperatures experienced in the field (gray histograms). Each species is represented by a single row, and each panel represents the growth response and thermal niche of a single age class. Age classes are defined in relation to the hatching date of single individuals in the field or in the lab and correspond to days 0-42 (left), 42-84 (center), and 84-126 (right). TPCs of size-corrected relative growth rates were estimated in the laboratory, and the frequency distributions of temperatures experienced by different age classes in the field were estimated from the simulations of larval hatching dates coupled to FLake temperature data. The 95\% CIs of RGRs have been drawn but are hidden behind the symbols. Drawings in the left column are by V. Nilsson-Örtman.

Significance levels of fixed effects were assessed by $F$ tests, whereas significance levels of random effects were assessed by likelihood ratio tests (Bolker et al. 2009), although variation at the level of random effects were not within the scope of this paper. It should be noted that although maternal effects have been found to be negligible in coenagrionids (Strobbe and Stoks 2004, Shama et al. 2011), nonadditive and maternal effects may be part of the (random) family effect.

\section{Statistical analysis of reaction norms}

Finally, we related the ontogenetic changes in TPC shape to changes in the two variables (average temperature and variability) that were used to describe the thermal niche of larvae in nature. An ideal approach to do so would include fitting a single, continuous function to each family's data, from which biologically meaningful parameters, such as the optimum, height, and breadth, could be estimated. These could then be 
compared directly among ontogenetic stages and related to measures of environmental variation (Clusella-Trullas et al. 2011). However, because we found that the reaction norms of most families were monotonically increasing within the experimental temperature range, a single, biologically meaningful model could not be fitted to all families. Instead, as the LMEs of age-specific RGRs revealed that differences in the slope of TPCs between time intervals explained about 16 times more variation than differences in curvature, we focused on variation in the slope of TPCs.

For each family, we estimated the TPC slope during early, intermediate, and late ontogeny. Similar to how we calculated rates of change of environmental parameters (Eq. 8), we also calculated the rate at which the slope of age-specific growth TPCs changed from early to intermediate and intermediate to late ontogeny. To calculate age-specific TPC slopes, we fitted separate ordinary least squares (OLS) regressions between RGR and temperature, with early, intermediate, or late RGRs as the response variable. In cases where RGRs were reduced at the highest temperature compared to the next highest (cf. Fig. 5D, J), only the three lower temperatures were used to fit the regression (as inclusion of the highest temperature would cause a downward bias driven by the curvature). Having estimated TPC slopes at each of the three time intervals, rates of change in the slope was calculated as

$$
\Delta \text { slope }=\frac{\left(S_{i}-S_{i-1}\right)}{42}
$$

where $\mathrm{S}_{i}$ is the slope parameter at time interval $i$ (i.e., early, intermediate, and late growth). To ensure robust parameter estimates and confidence intervals of TPC slope and $\Delta$ slope, each step of this process was bootstrapped 1000 times for each family. Thus, for each random bootstrap draw, we calculated: (1) the TPC slope during each ontogenetic stage, and (2) the corresponding rate of change from early to intermediate and intermediate to late ontogeny. Based on the 1000 bootstrap replicates, we calculated the mean, standard deviation and $95 \% \mathrm{CI}$ of both TPC slope and $\Delta$ slope.

To test if the rate of change in the thermal niche during ontogeny in the field (Eqs. 6 and 7) had an effect on how the slope of TPCs change during corresponding time intervals in the laboratory (Eq. 9), we performed two separate weighted ANOVAs. The rate of change in TPC slope between time intervals, $\Delta$ slope, was used as the response variable, with changes in either the mean, $\Delta$ mean, or variability, $\triangle \mathrm{MAD}$, of temperature during corresponding time intervals in nature were used as predictor variables. Because each family was represented by two estimates (describing the rate of change from early to intermediate and intermediate to late growth stages), we included the time interval and its interaction with environmental variables as fixed factors to test whether data from two time intervals displayed the same trend. To account for the uncertainty of the $\Delta$ slope estimates, we included the inverse of the squared variance of the $\Delta$ slope bootstrap estimates as weights. We carried out model simplification on the basis of AIC scores using the R function step. Significance levels of terms that were not included in the final model were calculated after introducing these terms singly (or together with lower order terms) into the reduced models.

All statistical analyses were performed in R 2.14.0 ( $\mathrm{R}$ Development Core Team 2008). The LME models were implemented using the function lmer in the $\mathrm{R}$ package lme4 (Bates et al. 2012).

\section{RESUlts \\ Latitudinal trends in phenology}

The literature survey of the phenology of 14 European Coenagrion spp. showed that the length of the flight season decreased with latitude, becoming, on average, 1.43 days shorter for every degree of latitude $\left(F_{1,98}=\right.$ 24.30, $P<0.001$; Fig. 4A). Differences in the timing of both the start and end of the flight season contributed to the decrease in length, as the start of the flight season occurred 1.02 days later with every degree of latitude $(t=$ 6.91, $P<0.001)$, and the end occurred 0.5 days earlier for every degrees of latitude $(t=-2.29, P=0.023)$. Neither trend was significantly nonlinear. Latitudinal trends of the six species used for the growth rate experiment (Fig. 4B-G) largely reflected the overall trend, as we found no significant species $\times$ latitude interaction either with respect to the length, or the start of the flight season (Table 2). Species did differ in the timing of their flight season (reflecting "early" and "late" flying species), as evidenced by significant species effects for each aspect of the flight season (Table 3). When each species was analyzed separately, several cases of nonlinear patterns were revealed. In $C$. puella and $C$. scitulum, the length of the flight season was longest in the central areas of the range, with reported flight times in the southern and northern part of their range being somewhat shorter (Fig. 4D, G). In C. pulchellum, emergence was slightly earlier at mid-latitudes (Fig. $4 \mathrm{E})$. The consequences of these phenological trends for the thermal environment experienced by individual larvae are treated next.

\section{Thermal niche shifts during ontogeny}

The simulations of larval hatching dates (Eq. 3) in combination with FLake temperature data revealed that all species experienced monotonically decreasing average temperatures during ontogeny in the field (Fig. 6A). Northern species experienced a uniform decrease, whereas southern and central species experienced a less steep change between the first and second age class, but a more rapid change between the second and third (Fig. $6 \mathrm{~A})$. With respect to thermal variability, all species experienced increasing variability during ontogeny (Fig. $6 \mathrm{~B})$. Southern species experienced less variation during early ontogeny than central and northern species, but 
TABLE 2. Results from linear mixed-effects models on the effects of temperature, ontogenetic stage, and species on relative growth rates.

\begin{tabular}{lrrr}
\hline \hline \multicolumn{1}{c}{ Variable } & \multicolumn{1}{c}{$\mathrm{df}$} & \multicolumn{1}{c}{$F$} & \multicolumn{1}{c}{$P$} \\
\hline Intercept $_{\text {Temperature }}$ & 1,2802 & 25245.573 & $<0.0001$ \\
Temperature $^{2}$ & 1,1549 & 2808.585 & $<0.0001$ \\
Ontogenetic stage $_{\text {Species }}$ & 1,1549 & 169.018 & $<0.0001$ \\
Ontogenetic stage $\times$ temperature & 2,2802 & 8562.783 & $<0.0001$ \\
Ontogenetic stage $\times$ temperature $^{2}$ & 5,11 & 228.269 & $<0.0001$ \\
Species $\times$ temperature $_{\text {Species } \times \text { temperature }}^{2}$ & 2,2802 & 124.522 & $<0.0001$ \\
Species $\times$ ontogenetic stage $\times$ temperature $^{2}$ & 2,2802 & 21.334 & $<0.0001$ \\
Species $\times$ ontogenetic stage $\times$ temperature $^{2}$ & 5,1549 & 51.951 & $<0.0001$ \\
Population & 5,1549 & 19.047 & $<0.0001$ \\
Family (population) & 10,2802 & 26.225 & $<0.0001$ \\
Individuals (family) & 1,48 & 31.703 & $<0.0001$ \\
& 1,48 & $2.690 \dagger$ & 0.1497 \\
\hline
\end{tabular}

$\dagger$ The $\chi^{2}$ value is shown, rather than $F$.

higher variability in older age classes. Taken together, the timing of early ontogeny coincided with high environmental temperatures and low levels of thermal variation in all species.

\section{Developmental plasticity of TPC shape}

The common garden experiment revealed that, although relative growth rates generally increased with temperature, the shape of TPCs changed in elevation, slope, and curvature depending on when size-corrected RGRs were estimated (Table 2, Fig. 5). Species also differed in the way by which the slope of TPCs changed during ontogeny, both with regards to slope $\left(\chi_{10,2802}^{2}=\right.$ 26.225, $P<0.001)$ and curvature $\left(\chi_{10,2802}^{2}=31.70, P<\right.$ 0.001) (Table 2).

Focusing on TPCs during the early growth stage (Fig. $5 \mathrm{~A}-\mathrm{F}), \mathrm{TPC}$ were relatively steep in all species, and the highest growth rates occurred at the highest experimental temperatures, suggesting that thermal optima are reached at or above $21.5-24.0^{\circ} \mathrm{C}$ in all species during early ontogeny. The precise shape of TPCs differed between species differing in latitudinal distribution, being upward-convex in southern species, upwardconvex to linear in central species, and upward-concave in northern species (Fig. 5), similar to what has previously been described when comparing growth rates of these species at a common reference size (NilssonÖrtman et al. 2012).

Focusing on growth patterns during the intermediate and late growth stages (Fig. 5G-R), the height, slope, and curvature of TPCs changes (Table 2). Four of the six species displayed significant changes in curvature compared to early growth (ontogenetic stage $\times$ temperature $^{2}$ interaction; Appendix C: Table C1), the exceptions being $C$. puella, which retained a linear TPC throughout the duration of the experiment (Fig. 5C, I, O; Appendix C: Table C1) and C. scitulum, which retained a similarly curved TPC throughout the experiment (Fig. 5E, K, Q; Appendix C: Table C1). The strongest observed difference in curvature was observed in C. pulchellum, where intermediate and late RGRs were slightly lower at $24^{\circ} \mathrm{C}$ than $21.5^{\circ} \mathrm{C}$ (Fig. 5J, P), which was not the case for early RGRs (Fig. 5D). This indicated that the older C. pulchellum larvae

TABle 3. Results from three two-way ANOVAs on the effects of species and latitude on different aspects of the phenology of six European Coenagrion species.

\begin{tabular}{lrrrr}
\hline \hline \multicolumn{1}{c}{ Model and variable } & df & MS & $F$ & $P$ \\
\hline A) Length of the flight season & & & & \\
$\quad$ Latitude & 1 & 23338.1 & 24.3041 & $<0.001$ \\
Species & 5 & 7012.8 & 7.3031 & $<0.001$ \\
Latitude $\times$ species & 5 & 1704.7 & 1.8525 & 0.1103 \\
$\quad$ Residuals & 93 & 920.2 & & \\
B) Start of the flight season & & & & \\
$\quad$ Latitude & 1 & 14413.6 & 40.4806 & $<0.001$ \\
Species & 5 & 1493.2 & 4.1936 & 0.0017 \\
Latitude $\times$ species & 5 & 594.8 & 1.7317 & \\
$\quad$ Residuals & 95 & 343.5 & & \\
C) End of the flight season & & & & \\
$\quad$ Latitude & 1 & 2539.4 & 5.1274 & 0.0258 \\
Species & 5 & 5897.4 & 11.9076 & 0.3984 \\
Latitude $\times$ species & 5 & 514.5 & 1.0411 & \\
Residuals & 93 & 494.2 & & \\
\end{tabular}

Note: Separate tests were performed on the (A) length, (B) start, and (C) end of the flight season. 

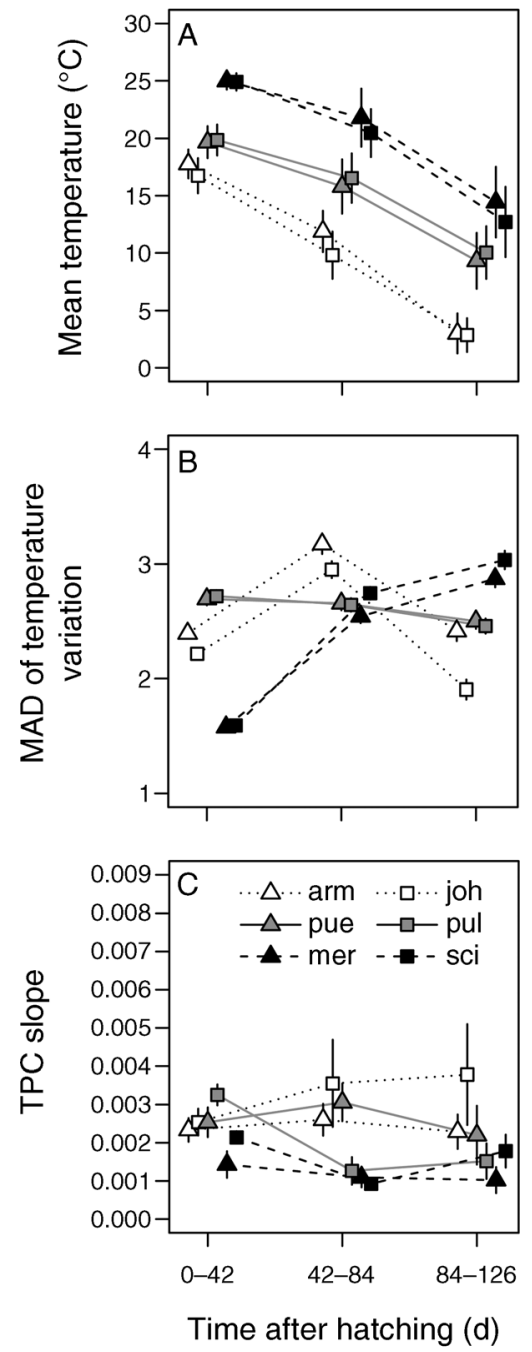

FIG. 6. (A, B) Ontogenetic shifts in the thermal niches in nature for the six studied species, and (C) ontogenetic changes in the slope of thermal performance curves when estimated in the laboratory. Changes in the (A) mean temperature and (B) thermal variability (median absolute deviation, MAD) during ontogeny was estimated by simulating larval hatching dates of each species (Eq. 3) and coupling these to simulated water temperature data from the lake model FLake. The three ontogenetic stages are defined relative to the hatching date of single individuals, namely, from hatching to day 42 (corresponding roughly to mid-July to end of August in nature), day 42 to 84 (end of August to early October), and day 84 to 126 (early October to mid-November). (C) The slope of TPCs of size-standardized relative growth rates when measured at three different ontogenetic stages. TPC slopes are calculated at the level of families $(N=120)$. Vertical lines in in each panel show 95\% CIs based on (A, B) 1000 simulated individuals or (C) 1000 bootstrap replicates. Abbreviation are: arm, Coenagrion armatum; joh, C. johanssoni; pue, C. puella; pul, C. pulchellum; mer, C. mercuriale; sci, C. scitulum. performed better at a lower temperature. In C. armatum, TPCs changed from being upward-concave during the early growth phase to being linear during later growth phases (Fig. 5B, H, N; Appendix C: Table C1). In $C$. johanssoni, TPCs were slightly upward-concave during early ontogeny (Fig. 5A), but became even more upward-concave during later ontogeny (Fig. 5G, M). Thus, the developmental plasticity of TPCs in $C$. johanssoni led to increased growth performance at high, rather than low, temperatures as larvae grew older. Overall, however, changes in curvature were relatively slight and explained a minor part of the total variation (Table 2; Appendix C: Table C1).

Developmental plasticity of the slope of TPCs explained almost 16 times more variation than changes in curvature (Table 2; interactions involving ontogenetic stage and temperature). In five of the six species, ontogenetic changes in the slope of TPCs were significant (Appendix C: Table C1). Slopes decreased over time in C. puella, $C$. pulchellum, and $C$. mercuriale (Figs. 5C, D, F and 6C). In C. scitulum, the slope first decreased from early to intermediate ontogeny (Figs. $5 \mathrm{E}, \mathrm{K}$ and $6 \mathrm{C}$ ), but then increased from intermediate to late ontogeny (Figs. 5K, Q and 6C). C. armatum was the only species that did not show any significant developmental plasticity of TPC shape (Figs. 5B, H, N and 6C; Appendix C: Table C1A). In C. johanssoni, the slope of reaction norms increased over time (Figs. 5A, G, M and 6C).

\section{Environmental drivers of ontogenetic TPC shifts}

The ANOVA of the relationship between $\Delta$ slope and $\Delta$ mean revealed that the amount of developmental plasticity of TPCs correlated significantly with the rate of change in mean temperatures experienced in the field (Table 4A). The relationship between $\Delta$ slope and $\Delta$ mean was observed regardless of whether we compared early with intermediate, or intermediate with late ontogenetic stages (Fig. 7A; nonsignificant interaction between ontogenetic stage and $\Delta$ mean in Table $4 \mathrm{~A}$ ). The direction of this relationship, however, was the opposite of the predicted relationship. Thus, the most dramatic decreases in TPC slope during ontogeny were observed in those cases when larvae experienced small changes in average temperature in nature. Thus, early and intermediate growth stages of central and southern species displayed the most pronounced developmental plasticity of TPCs. Conversely, we observed small negative or even positive changes in the slope of TPCs during ontogeny in those larvae that experienced the most rapid changes in average temperatures in the field. In other words, the developmental plasticity of TPCs was weak or TPC slopes increased in northern species and in later growth stages of southern and central species (Fig. 5). The ANOVA of the relationship between $\Delta$ slope and $\triangle \mathrm{MAD}$ revealed no clear relationship to thermal variability (Table $4 \mathrm{~B}$ ) and the $\triangle \mathrm{MAD}$ term was excluded from the final model (Table 4B, Fig. 7B). 
TABLE 4. Results from linear mixed-effects models on the effects of ontogenetic stage and rates of change in (A) mean temperature and (B) thermal variability on rates of change of the slope of the thermal performance curve (TPC) during ontogeny.

\begin{tabular}{lrrrr}
\hline \hline \multicolumn{1}{c}{ Variable } & Estimate & SE & $t$ & $P$ \\
\hline A) Mean temperature & & & & \\
$\quad$ Intercept $\dagger$ & -0.016 & 0.064 & -0.254 & 0.800 \\
$\Delta$ mean $\dagger$ & -0.439 & 0.062 & -7.069 & $<0.001$ \\
Ontogenetic stage & 0.141 & 0.268 & 0.527 & 0.599 \\
Ontogenetic stage $\times \Delta$ mean & -0.427 & 0.331 & -1.289 & 0.199 \\
B) Thermal variability & & & & \\
Intercept $\dagger$ & 0.347 & 0.110 & 3.159 & 0.002 \\
Ontogenetic stage $\dagger$ & -0.766 & 0.136 & -5.651 & $<0.001$ \\
$\Delta$ MAD & 0.044 & 0.086 & 0.508 & 0.612 \\
Ontogenetic stage $\times \Delta$ MAD & -0.098 & 0.205 & -0.479 & 0.633 \\
\hline
\end{tabular}

Note: Significance levels of excluded terms were calculated after introducing them singly into the minimal models. MAD stands for median absolute deviation.

$\dagger$ These terms were included in the minimal models after model simplification based on AIC scores.

\section{DisCUSSION}

Our investigation of the interacting effects of phenology and age-specific thermal performance offers several insights into the adaptive significance of the shape and developmental plasticity of thermal performance curves (TPCs). We detected ontogenetic shifts of TPC shape in all species: In five out of six species, TPCs changed in slope during ontogeny, and in four species, the curvature changed. Two main observations emerge from these results. First, that the shapes of TPCs during different stages of development may be involved in trade-offs. Second, that there are limits to how fast species can adjust their physiology in order to track changes in the thermal niche during ontogeny. Our findings reinforce the emerging view that performance measured at a single ontogenetic stage will not be sufficient to predict species'

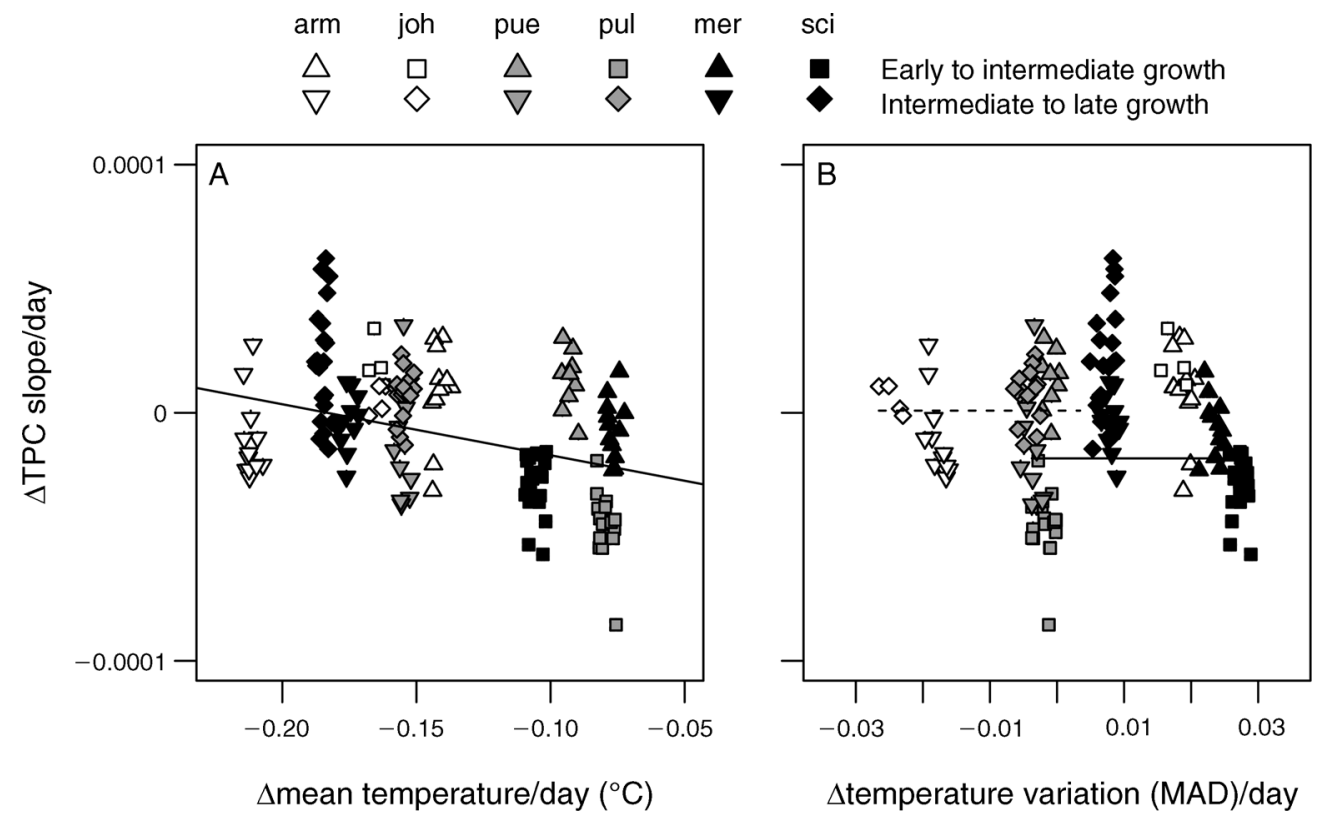

FIG. 7. The relationship between the rates at which the slope of reaction norms of growth rates change during ontogeny $(\Delta \mathrm{TPC}$ slope) and the rates at which aspects of species' thermal environment change during ontogeny in the field. In panel (A), the $\triangle$ TPC slope is plotted against the rate of change in mean temperature in the field ( $\Delta$ mean). Note that the scale along the $x$-axis is negative, so that lower values of $\Delta$ mean represent more rapid changes in temperatures. In panel (B), the $\Delta$ TPC slope is plotted against the rate of change in thermal variability, characterized as the median absolute deviation of temperatures experienced by a given age class in nature. Each symbol represents a single family group. Rate of change is defined as the change in the variable of interest from one age class to the next. Because we considered three age classes here (early, intermediate, and late), each family is represented by two values: One symbol is used to denote the rate of change between the early to intermediate growth stage, and one symbol is used to denote the rate of change between the intermediate to late growth stage (see key). The solid line in panel (A) shows the best predictor of changes in thermal performance during ontogeny: a linear, negative relationship between $\triangle$ TPC slope and $\Delta$ mean. Values along the $x$-axis have been jittered for clarity. Species abbreviations are as in Fig. 6. 
responses to climate change (Yang and Rudolf 2009, Kingsolver et al. 2011, Régnière et al. 2012).

We hypothesized that the length of the flight season would be important for understanding differences in the amount of developmental plasticity of TPCs. A long reproductive season at lower latitudes was expected to result in unpredictable larval conditions, favoring obligate generalists in Southern Europe (Fig. 1A). Conversely, more synchronized reproduction at high latitudes was expected to favor strong ontogenetic shifts from initial specialization to later generalization in North European species (Fig. 1C). These predictions were not supported. Firstly, Northern species displayed small changes in TPC shape during ontogeny, or even an increase in the slope of TPCs, compared to other species (Fig. 5, two top rows). Secondly, southern species were found to experience less thermal variability during early growth stages compared to species from higher latitudes (Fig. 6B), despite having longer flight seasons (Fig. 4A). Thus, the long warm summers at lower latitudes had a greater influence on early larval growth conditions than did the phenological timing of reproduction. This result, however, may not generalize directly to other systems. In taxa that display stronger differences in phenological timing, differences in the timing of reproduction may have much greater influences relative to climatic differences than observed here.

The best predictor of the strength and direction of developmental plasticity of TPCs was whether a species experienced slow or rapid changes in average temperatures during ontogeny in nature (Fig. 7A). The direction of this relationship was unexpected: If temperature changed slowly in the field, changes in the slope of TPCs were strong and negative when larvae were grown in the laboratory. Conversely, when average temperature changed rapidly, changes in the slope of reaction norms were small or positive (Fig. 7A; note that the $x$-axis is negative, a $\Delta$ mean of -0.20 thus represents a more rapid change in temperature than a $\Delta$ mean of -0.05 ). In other words: Larvae from highly seasonal high-latitude environments became relatively better at growing at high temperatures as they grew older. Larvae from less seasonal low-latitude environments instead became relatively better at growing at low temperatures as they grew older.

In the following sections we will outline our interpretation of these results. Again, it should be noted that we cannot separate acclimation responses (Fig. 1B) from fixed, ontogenetic shifts (Fig. 1C), but our main conclusions do not hinge on the precise mechanism underlying ontogenetic changes in the shape of TPCs. The key points in our interpretation of these results are that: (1) the optimal shape of TPCs differs among ontogenetic stages; (2) the shape of TPCs is correlated across the ontogeny, but can be modified through developmental plasticity; (3) the strength of selection on TPC shape varies during ontogeny; and (4) the costs and benefits of developmental plasticity of TPCs varies with the rate of change in average temperature.

\section{Performance trade-offs between ontogenetic stages}

That reaction norms were steeper during early (Fig. 5A-F), compared to later growth stages (Figs. 5G-R and $6 \mathrm{C}$ ), in four out of six species matches the expected direction based on how the thermal niche change during ontogeny in nature (Fig. 6A, B). This observation corresponds to other studies that have shown how later ontogenetic stages (occurring primarily towards the end of the growth season) perform better at lower temperatures than early growth stages (occurring primarily during the summer; Schultz et al. 1996, van Doorslaer and Stoks 2005). Upon closer inspection, however, the match is only partial, even in those species that display this pattern: There is a much closer agreement between thermal performance (in the laboratory) and the thermal niche (in nature) during early ontogeny (Fig. 5A-F; cf. reaction norms in black with the frequency distribution of temperatures in gray) than during later growth stages (Fig. 5G-R). Our interpretation of this is that it may reflect a trade-off between growth performance during early vs. late ontogeny, together with that selection favors specialization to early growth conditions even at the cost of a reduction in growth performance during later stages. Several factors could contribute to this; for example, density-dependent cannibalism, which is widespread in damselfly larvae (Anholt 1994, Mikolajewski et al. 2008). Because densities (and consequently mortality rates) are highest immediately following hatching, even a very small size advantage during early ontogeny will confer substantial fitness benefits (Hopper et al. 1996). Alternatively, because the strength of competition and predation tends to increase with temperature (Park 1954, Spitze 1985, Brown et al. 2004), selection on growth performance will be strongest immediately following hatching when temperatures are highest (Fig. 6A).

Additionally, kinetic effects have been suggested to make it impossible for individuals to achieve as high performance at low temperatures as at higher temperatures, the so-called hotter-is-better hypothesis (Knies et al. 2009, Angilletta et al. 2010). Because of this, individuals may have more to gain by focusing their growth efforts to periods of high temperatures during early ontogeny. Each of these three mechanisms may favor specialization to early growth conditions at the expense of a reduction in growth potential during later stages. If such trade-offs are indeed important, it strongly suggests that measures of variation averaged over the entire life cycle (e.g., Lynch and Gabriel 1987, Gilchrist 1995, Asbury and Angilletta 2010) will not be sufficient to explain variation in thermal performance curves. Although allocation and acquisition trade-offs such as these are common assumptions in life history theory and in optimality models of phenotypic plasticity, their existence have remained notoriously difficult to demonstrate empirically (Angilletta et al. 2003, Nylin and Gotthard 1998) and must be interpreted cautiously. 


\section{Strength and direction of developmental plasticity}

Our result showed that developmental plasticity of TPCs was strong (rapid) and in favor of increased lowtemperature performance when temperatures changed slowly in nature. In contrast, developmental plasticity was weak (slow) or showed the reversed pattern (increased high-temperature performance during late ontogeny) when temperatures changed rapidly in nature. This indicates that developmental plasticity of TPCs can be important for allowing individuals to maintain relatively high performance also when temperatures decrease towards the end of the growth season. It, however, also suggests that whether strong acclimation responses will evolve likely depend on several factors that affect the costs and benefits of acclimation. Acclimation involves a great number of energetically costly physiological changes (Hoffmann 1995, Huey and Berrigan 1996, Ellers et al. 2008), and very rapid acclimation is presumably much more costly (or even impossible) than slow acclimation (Kelty and Lee 1999). In addition, how much more an individual will be able to grow by acclimating will depend both on how much it can increase in growth performance at a given temperature and on how much time is spent at that temperature (Kingsolver et al. 2001). When temperatures decrease more rapidly (i.e., in high-latitude environments), less time will be spent at each successive temperature, resulting in a decrease in the benefits that can be gained from acclimating. How an increase in performance translates into fitness will also likely change over the season. Again, because the strength of competition and predation likely increase with temperature (Brown et al. 2004), there will be less strong selection due to ecological interactions as temperatures decreases. We consider it likely that all these factors contribute to the observation that acclimation responses are weakest when temperature changes rapidly over an individual's ontogeny (Fig. 7A).

These patterns of phenology and physiological acclimation could have a considerable impact on the dynamics of damselfly populations. In many organisms, including damselflies, population dynamics are greatly affected by competition and predator-prey interactions (Sih et al. 1985) and the outcome of these interactions often depend on the relative size and growth rates of individuals (Persson and De Roos 2006, Rudolf 2008). Because of differences in the timing of hatching, shape of TPCs, and strength of acclimation, the type and strength of interactions that occur among individuals are likely to change over the course of the growth season (Yang and Rudolf 2009). Consider, for example, a hypothetical scenario where the six species studied here occur at the same sites and the outcomes of competitive interactions are lethal and size dependent (Johansson 1996). During early ontogeny, when temperatures are high, species with steep early TPCs (northern and central species; Fig. 5A-D) would increase rapidly in size and prey upon the smaller, thermally generalized southern species (Fig. 5E, F). Later in the season, however, the competitive dominance would shift in favor of thermally generalized southern species (Fig. $5 \mathrm{E}, \mathrm{K}, \mathrm{G}, \mathrm{F}, \mathrm{L}, \mathrm{R})$ and the strongly acclimating $C$. pulchellum (Fig. 5D, J, P). This suggests that the outcome of species interactions under climate change may, in part, depend on whether warming will be strongest during the hotter months (presumably favoring species with steep early growth TPCs such as $C$. johanssoni) or during the colder months (leading to a longer growth season, favoring obligate generalists such as C. scitulum or species with strong acclimation responses such as $C$. pulchellum).

Several additional factors may also be important to consider in order to explain the observed differences in TPC shape and strength of acclimation response. One such factor is latitudinal variation in voltinism. In predominantly univoltine southern and central species, individuals have only one chance: Following their first summer, fall, and spring, they must be ready to emerge. Individuals that fail to emerge the next spring will effectively reduce their fitness by half, compared to individuals that complete their larval development in a single year (Huey and Berrigan 2001, Kingsolver and Huey 2008). Because of this, selection may strongly favor individuals that are able to grow relatively fast during fall and spring in univoltine species. Semivoltine northern species, on the other hand, have an entire extra summer season available for growth. Because of this, growth during fall and spring may less important in determining whether or not an individual is able to emerge in synchrony with other members of its cohort.

Differences among ontogenetic stages in diet also represent a potential confounding factor. Detailed data on ontogenetic dietary shifts is lacking for damselflies, but larvae are generally able to exploit larger prey as they grow older (Corbet 1999). It is thus possible that the food used here, Artemia salina, are more appropriate during certain stages of ontogenetic development. In general, however, experiments with damselfly larvae have shown strong agreement regardless of whether researchers used smaller Artemia salina, larger Daphnia magna or other food sources during rearing (Pierce et al. 1985, Baker 1989, Stoks et al. 2005; Nilsson-Örtman et al. 2014), indicating that the influence of diet preferences is relatively weak.

In addition, genetic constraints may affect the evolution of acclimation responses. Such constraints may either stem from a lack of additive genetic variation or from genetic correlations with other traits (Via and Lande 1985, Scheiner 1993). At present, virtually nothing is known about genetic variances and covariances of acclimation responses (Kingsolver and Huey 1998, Angilletta 2009). It is therefore difficult to assess whether genetic constraints may play a role here.

The differences we observed among species within the Northern and Central European species pairs are intriguing. Despite having relatively similar distributions 
(Fig. 2), the northern $C$. johanssoni displayed a significant increase in TPC slope during ontogeny (Fig. $5 \mathrm{~A}, \mathrm{G}, \mathrm{M}$ ), whereas $C$. armatum did not (Fig. 5B, H, N). Likewise, the central $C$. pulchellum displayed a marked change in the shape of TPCs during intermediate and late ontogeny (Fig. 5D, J, P), whereas its sister species $C$. puella did not (Fig. 5C, I, O). We can only speculate about the possible reasons for these differences. In the case of the two northern species, habitat differences may play a role. Of these, $C$. johanssoni is restricted to acidic, species-poor bog habitats, whereas $C$. armatum occur at nutrient-rich sites. This may suggest that factors such as predation, competition, and resource availability can modify the costs and benefits of low-temperature acclimation. Living in an environment with less intense competition, $C$. johanssoni may have less to gain from acclimating to low temperatures towards the end of the growth season than C. armatum. Alternatively, differences in voltinism patterns may play a role for these differences as well. Although detailed information about voltinism is scarce for northern species, $C$. johanssoni presumably require two or more years per generations over much of its range (Corbet et al. 2006). Since C. armatum has a slightly less extreme high-latitude distribution (cf. Fig. 2A, B), it may be able to maintain a univoltine life cycle over at least part of its range (Johansson and Norling 1994, Corbet et al. 2006). These possible links between voltinism patterns, seasonal timing of growth, and developmental plasticity would certainly merit further theoretical and empirical exploration.

Differences observed among the two central species are more difficult to explain as these two species are very closely related (Lowe et al. 2008) and have almost identical distributions (Fig. 2C, D). Intriguingly, ontogenetic patterns of thermal performance were virtually identical in the central C. puella (Fig. 5C, I, O) and the northern $C$. armatum (Fig. 5B, H, N). At present, the causes behind these unexpected findings remain obscure. Regardless of their evolutionary causes, idiosyncrasies among sympatric species such as those observed here indicate that it may be difficult to generalize about species' responses to changing temperatures based solely on current distribution patterns (Beale et al. 2008).

\section{Determinants of the shape of TPCs}

We hypothesize that thermal specialization to early growth occurs at the expense of reduction in growth performance during later stages. This is based on the observation that the agreement between individuals' growth performance and their thermal niche was greater during early ontogeny (Fig. 5A-F) than during later stages (Fig. 5G-R). Optimality models predict that thermal optima should match the mean or modal environmental temperatures (Lynch and Gabriel 1987, Gilchrist 1995), and we would expect the shape of TPCs to match the distribution of temperatures (Kingsolver et al. 2001). However, a closer look at early growth performance (Fig. 5A-F) reveals intriguing deviations from these predictions. In particular, the agreement is most evident in southern species: High thermal optima $\left(24^{\circ} \mathrm{C}\right.$ or higher) and relatively steep TPCs during early ontogeny mirrors that this age class rarely experience temperatures much lower than $20^{\circ} \mathrm{C}$ in nature (Fig. 5E, F). Central and North European species, on the other hand, display even steeper TPCs during early ontogeny than southern species and maintain thermal optima above $21.5-24.0^{\circ} \mathrm{C}$; despite that, this age class only rarely experiences such high temperatures in nature (Fig. 5A-D). That northern species have high thermal optima in relation to conditions experienced over the entire life cycle has previously been pointed out (Nilsson-Örtman et al. 2012). The results of this study show that even if we interpret TPCs of northern species in relation to conditions experienced during only the warmest and least variable part of the growth season, thermal optima still fall well above modal temperatures (Fig. 5A, B). These observations fit with an increasing number of studies documenting how thermal optima are typically higher than modal environmental temperatures (Bennett 1987, Knies et al. 2009, Angilletta et al. 2010). Because the species studied here have evolved from tropical ancestors, high thermal optima could reflect evolutionarily constraints on the shape of TPCs. However, because the shape of early growth TPCs of northern species is strikingly different from southern species, early TPCs are likely not entirely a result of evolutionary conservatism. Also, we have previously interpreted the near-exponential TPCs of northern species to be indicative of thermal specialization (Nilsson-Örtman et al. 2012). In that study, we suggested that this may reflect that these species enter a larval diapause at temperatures below $8^{\circ} \mathrm{C}$. In highlatitude environments, temperatures rapidly fall below the temperature threshold (Fig. 6A), resulting in a reduction in the amount of temperature variation experienced during periods of active growth in highlatitude species. The present data does not conflict with this interpretation.

In addition, the hotter-is-better hypothesis (Angilletta et al. 2010) invoked above in the subsection Performance trade-offs between ontogenetic stages to explain differences among growth stages may also alter the optimal shape of TPCs during early ontogeny. In other words, even if organisms encounter high temperatures relatively infrequently (i.e., during early growth of $C$. puella and $C$. pulchellum; Fig. 5C, D), it may be beneficial to optimize growth at higher temperatures than the modal temperature, as even short exposures to high temperatures will allow significant gains (Kingsolver 2000). But why do southern species display upward-convex TPCs during early ontogeny (Fig. 5E, F), while northern species display upward-concave TPCs during the same growth phase (Fig. 5A, B)? Possibly the fact that southern species spend more time at low and intermediate temperatures (but above the diapause threshold) during 
later ontogeny could lead to increased selection for lowtemperature performance that carries over into the TPCs of early ontogeny. The thermal characteristics of $C$. mercuriale (Fig. 5F, L, R) is especially interesting in this regard, as this is the species that comes nearest to being an obligate thermal generalist (cf. Fig. 1A with Fig. $5 \mathrm{~F}, \mathrm{~L}, \mathrm{R})$. This species also displays a relatively steep increase in the length of the flight season towards lower latitudes (Fig. 4F). This may lend some credence to the hypothesized link between a long reproductive season and obligate thermal generalization, although further research should attempt to reveal whether reproduction may be less seasonal in this species than was assumed here, or if the fitness of individuals hatching from eggs deposited early or late in the season differ markedly (De Block and Stoks 2005, Varpe et al. 2007).

The FLake simulations used here are a great tool, as they can greatly help alleviate the lack of high-resolution water temperature data. However, reaching a complete understanding of aquatic invertebrates' thermal environment is a challenging task and the FLake simulations may not capture the whole range of conditions that individual larvae are exposed to in the field. For example, both microhabitat heterogeneity and diurnal fluctuations may contribute to substantial variation. Although behavioral thermoregulation has not yet been demonstrated in these species, it is known that they spend much time close to the surface (Johansson 2000). As near-surface temperatures at $C$. armatum sites at $51^{\circ} \mathrm{N}$ may reach as high as $27^{\circ} \mathrm{C}$ during peak hours in some days (V. Nilsson-Örtman, unpublished data), there may be room for significant heat gains, although such a behavior would likely confer trade-offs; for example, through an increased risk of predation. Preliminary simulations suggest that if individuals of the two northern species can gain approximately $4-5^{\circ} \mathrm{C}$ over simulated temperatures for a few hours on most days during summer, they would achieve a thermal environment that matches that seen here for Central European species (e.g., Fig. 5D).

\section{Concluding remarks}

Our results present a much more dynamic view of thermal performance than typically presented in empirical studies or captured by optimality models (e.g., Asbury and Angilletta 2010). Importantly, we find that the thermal sensitivity of growth rates changes during ontogeny and that these changes reflect changes in thermal conditions experienced by corresponding age classes in nature. However, performance of successive stages does not appear to be independent and our results highlight several potential trade-offs that may be of ecological importance. The first is that a species' thermal strategy may reflect fitness trade-offs between growth during early and late ontogeny. For example, high mortality coupled with warm and stable thermal conditions during early ontogeny may select for initial thermal specialization even at the expense of a reduction in growth potential during later stages (cf. C. johanssoni in Fig. 5A, G, M). Conversely, if much time is spent at low and intermediate temperatures during late ontogeny, selection for low-temperature performance may occur at the expense of growth during early stages (cf. C. mercuriale in Fig. 5F, L, R). The second is a trade-off between adult phenology and larval thermal requirements: The timing of adult emergence may have evolved to ensure that larvae experience warm and stable conditions during early ontogeny (De Block and Stoks 2005, Varpe et al. 2007). This contrasts with the widespread notion that the activity periods of adult insects reflect thermal requirements of adults (Wolda 1988). Finally, our study highlights the importance of developmental plasticity of TPCs as a way for individuals to maintain relatively high performance in variable, but seasonally predictable, environments. The correlation between the strength of acclimation responses and rate of temperature change (Fig. 7A) suggests a novel hypothesis of how acclimation evolves: that acclimation is more beneficial to individual organisms and/or less costly when temperature changes more gradually (Huey and Berrigan 1996). Taken together, these results suggest that measures of environmental variation averaged across entire generations (Lynch and Gabriel 1987, Gilchrist 1995) will not be sufficient to explain variation in TPCs. We strongly caution against using the results from studies of single ontogenetic stages to predict species responses to climate change.

Future studies should strive to adopt a broad ecological perspective on thermal performance. In particular, researchers should take advantage of the vast amount of phenological information that is available in the zoological and botanical literature. A promising arena for inquiry would be to apply the approach presented here to systems with greater differences in phenological strategies. For example, do species whose early stages occur in early spring show the reversed ontogenetic pattern (i.e., cold-adapted early stages followed by heat-specialized later stages) to species whose early stages occur in late summer? Can environmental cues induce changes in the ontogenetic pattern of acclimation, for example, among spring and summer generation in biannual species? Have species with multiple, overlapping generations evolved to be obligate generalists? Several groups of plants, butterflies, beetles, wasps, flies, plants, frogs, and fish hold the promise to be ideal subjects for testing these questions.

\section{ACKNOWLEDGments}

V. Nilsson-Örtman, R. Stoks, M. De Block, and F. Johansson conceived the study and performed the laboratory experiment; V. Nilsson-Örtman developed the computer model, analyzed data, and wrote the paper; R. Stoks, M. De Block, and F. Johansson contributed to writing. M. De Block is a postdoctoral fellow of the Fund for Scientific ResearchFlanders (FWO). Financial support to R. Stoks came from FWO and the KULeuven research fund, and financial support to V. Nilsson-Örtman and F. Johansson came from the Swedish 
Research Council Formas. We thank all those that have helped us to locate suitable sampling sites.

\section{Literature Cited}

Angilletta, M. J. 2009. Thermal adaptation: a theoretical and empirical synthesis. Oxford University Press, Oxford, UK.

Angilletta, M. J., Jr., A. F. Bennett, H. Guderley, C. A. Navas, F. Seebacher, and R. S. Wilson. 2006. Coadaptation: a unifying principle in evolutionary thermal biology. Physiological and Biochemical Zoology 79:282-294.

Angilletta, M. J., Jr., R. B. Huey, and M. R. Frazier. 2010. Thermodynamic effects on organismal performance: is hotter better? Physiological and Biochemical Zoology 83:197-206.

Angilletta, M. J., R. S. Wilson, C. A. Navas, and R. S. James. 2003. Tradeoffs and the evolution of thermal reaction norms. Trends in Ecology and Evolution 18:234-240.

Anholt, B. R. 1994. Cannibalism and early instar survival in a larval damselfly. Oecologia 99:60-65.

Asbury, D. A., and M. J. Angilletta, Jr. 2010. Thermodynamic effects on the evolution of performance curves. American Naturalist 176:E40-E49.

Askew, R. R. 2004. The dragonflies of Europe. Revised edition. Harley Books, Colchester, UK.

Atkin, O. K., D. Bruhn, V. M. Hurry, and M. G. Tjoelker. 2005. Evans Review No. 2: The hot and the cold: unravelling the variable response of plant respiration to temperature. Functional Plant Biology 32:87-105.

Baker, R. L. 1989. Condition and size of damselflies: a field study of food limitation. Oecologia 81:111-119.

Bates, D., M. Maechler, and B. Bolker. 2012. lme4: linear mixed-effects models using S4 classes. $\mathrm{R}$ package version 0.999999-0. http://CRAN.R-project.org/package=lme4

Beale, C. M., J. J. Lennon, and A. Gimona. 2008. Opening the climate envelope reveals no macroscale associations with climate in European birds. Proceedings of the National Academy of Sciences USA 105:14908-14912.

Bennett, A. F. 1987. Evolution of the control of body temperature: Is warmer better? Pages 421-431 in P. Dejours, L. Bolis, C. R. Taylor, and E. R. Weibel, editors. Comparative physiology: life in water and on land. Liviana, Padua, Italy.

Bentz, B. J., J. A. Logan, and G. D. Amman. 1991. Temperature-dependent development of the mountain pine beetle (Coleoptera: Scolytidae) and simulation of its phenology. Canadian Entomologist 123:1083-1094.

Berger, D., M. Friberg, and K. Gotthard. 2011. Divergence and ontogenetic coupling of larval behaviour and thermal reaction norms in three closely related butterflies. Proceedings of the Royal Society B 278:313-320.

Bolker, B. M., M. E. Brooks, C. J. Clark, S. W. Geange, J. R. Poulsen, M. H. H. Stevens, and J. S. S. White. 2009. Generalized linear mixed models: a practical guide for ecology and evolution. Trends in Ecology and Evolution 24:127-135.

Bowler, K., and J. S. Terblanche. 2008. Insect thermal tolerance: What is the role of ontogeny, ageing and senescence? Biological Reviews 83:339-355.

Bradshaw, W. E., and C. M. Holzapfel. 2001. Genetic shift in photoperiodic response correlated with global warming. Proceedings of the National Academy of Sciences USA 98:14509-14511.

Brown, J. H., J. F. Gillooly, A. P. Allen, V. M. Savage, and G. B. West. 2004. Toward a metabolic theory of ecology. Ecology 85:1771-1789.

Clusella-Trullas, S., T. M. Blackburn, and S. L. Chown. 2011. Climatic predictors of temperature performance curve parameters in ectotherms imply complex responses to climate change. American Naturalist 177:738-751.

Cooper, B. S., M. Czarnoleski, and M. J. Angilletta. 2010 Acclimation of thermal physiology in natural populations of Drosophila melanogaster: a test of an optimality model. Journal of Evolutionary Biology 23:2346-2355.
Corbet, P. S. 1999. Dragonflies: behavior and ecology of Odonata. Cornell University Press, Ithaca, New York, USA.

Corbet, P., F. Suhling, and D. Soendgerath. 2006. Voltinism of Odonata: a review. International Journal of Odonatology 9:1-44.

Cunningham, S. C., and J. Read. 2002. Do temperate rainforest trees have a greater ability to acclimate to changing temperatures than tropical rainforest trees? New Phytologist 157:55-64.

Danks, H. V. 2006. Key themes in the study of seasonal adaptations in insects II. Life-cycle patterns. Applied Entomology and Zoology 41:1-13.

Davidson, E. A., and I. A. Janssens. 2006. Temperature sensitivity of soil carbon decomposition and feedbacks to climate change. Nature 440:165-173.

Davis, C. C., C. G. Willis, R. B. Primack, and A. J. MillerRushing. 2010. The importance of phylogeny to the study of phenological response to global climate change. Philosophical Transactions of the Royal Society B 365:3201-3213.

De Block, M., and R. Stoks. 2005. Fitness effects from egg to reproduction: bridging the life history transition. Ecology 86:185-197.

Demont, M., W. U. Blanckenhorn, D. J. Hosken, and T. W. J. Garner. 2008. Molecular and quantitative genetic differentiation across Europe in yellow dung flies. Journal of Evolutionary Biology 21:1492-1503.

Deutsch, C. A., J. J. Tewksbury, R. B. Huey, K. S. Sheldon, C. K. Ghalambor, D. C. Haak, and P. R. Martin. 2008. Impacts of climate warming on terrestrial ectotherms across latitude. Proceedings of the National Academy of Sciences USA 105:6668.

Dillaway, D. N., and E. L. Kruger. 2010. Thermal acclimation of photosynthesis: a comparison of boreal and temperate tree species along a latitudinal transect. Plant, Cell and Environment 33:888-899.

Dreyer, E., X. Le Roux, P. Montpied, F. A. Daudet, and F. Masson. 2001. Temperature response of leaf photosynthetic capacity in seedlings from seven temperate tree species. Tree Physiology 21:223-232.

Ellers, J., J. Mariën, G. Driessen, and N. M. van Straalen. 2008. Temperature-induced gene expression associated with different thermal reaction norms for growth rate. Journal of Experimental Zoology Part B: Molecular and Developmental Evolution 310:137-147.

Feder, J. L., T. A. Hunt, and L. Bush. 1993. The effects of climate, host plant phenology and host fidelity on the genetics of apple and hawthorn infesting races of Rhagoletis pomonella. Entomologia Experimentalis et Applicata 69:117-135.

Forrest, J., and A. J. Miller-Rushing. 2010. Toward a synthetic understanding of the role of phenology in ecology and evolution. Philosophical Transactions of the Royal Society B 365:3101-3112.

Gabriel, W. 1999. Evolution of reversible plastic responses: inducible defenses and environmental tolerance. Pages $286-$ 305 in R. Tollrian and D. Harvell, editors. The ecology and evolution of inducible defenses. Princeton University Press, Princeton, New Jersey, USA.

Gabriel, W., and M. Lynch. 1992. The selective advantage of reaction norms for environmental tolerance. Journal of Evolutionary Biology 5:41-59.

Gilchrist, G. W. 1995. Specialists and generalists in changing environments. I. Fitness landscapes of thermal sensitivity. American Naturalist 146:252.

Guderley, H., Leroy, and Gagné. A. 2001. Thermal acclimation, growth, and burst swimming of threespine stickleback: enzymatic correlates and influence of photoperiod. Physiological and Biochemical Zoology 74:66-74.

Gunderson, C. A., K. H. O'Hara, C. M. Campion, A. V. Walker, and N. T. Edwards. 2010. Thermal plasticity of photosynthesis: the role of acclimation in forest responses to a warming climate. Global Change Biology 16:2272-2286. 
Hampel, F. R., E. M. Ronchetti, P. J. Rousseeuw, and W. A. Stahel. 1986. Robust statistics: the approach based on influence functions. Wiley, New York, New York, USA.

Hoffmann, A. A. 1995. Acclimation: increasing survival at a cost. Trends in Ecology and Evolution 10:1-1.

Hopper, K. R., P. H. Crowley, and D. Kielman. 1996. Density dependence, hatching synchrony, and within-cohort cannibalism in young dragonfly larvae. Ecology 77:191-200.

Huey, R. B., and D. Berrigan. 1996. Testing evolutionary hypotheses of acclimation. Pages 205-237 in A. Johnston, and A. F. Bennett, editors. Animals and temperature: Phenotypic and evolutionary adaptation. Cambridge University Press, Cambridge, UK.

Huey, R. B., and D. Berrigan. 2001. Temperature, demography, and ectotherm fitness. American Naturalist 158:204-210.

Johansson, F. 1996. The influence of cannibalism and prey density on growth in the damselfly Coenagrion hastulatum. Archiv für Hydrobiologie 137:523-535.

Johansson, F. 2000. The slow-fast life style characteristics in a suite of six species of odonate larvae. Freshwater Biology 43:149-159.

Johansson, F., and U. Norling. 1994. A five year study of the larval life history of Coenagrion hastulatum (Charpentier) and C. armatum (Charpentier) in northern Sweden (Zygoptera: Coenagrionidae). Odonatologica 23:355-364.

John-Alder, H. B., P. J. Morin, and S. Lawler. 1988. Thermal physiology, phenology, and distribution of tree frogs. American Naturalist 132:506-520.

Kattge, J., and W. Knorr. 2007. Temperature acclimation in a biochemical model of photosynthesis: a reanalysis of data from 36 species. Plant, Cell and Environment 30:1176-1190.

Kelty, J. D., and R. E. Lee, Jr. 1999. Induction of rapid cold hardening by cooling at ecologically relevant rates in Drosophila melanogaster. Journal of Insect Physiology 45:719-726.

Kingsolver, J. G. 2000. Feeding, growth, and the thermal environment of cabbage white caterpillars, Pieris rapae L. Physiological and Biochemical Zoology 73:621-628.

Kingsolver, J. G., and R. Gomulkiewicz. 2003. Environmental variation and selection on performance curves. Integrated and Comparative Biology 43:470-477.

Kingsolver, J. G., R. Gomulkiewicz, and P. A. Carter. 2001. Variation, selection and evolution of function-valued traits. Genetica 112-113:87-104.

Kingsolver, J. G., and R. B. Huey. 1998. Evolutionary analyses of morphological and physiological plasticity in thermally variable environments. American Zoologist 38:545-560.

Kingsolver, J., and R. Huey. 2008. Size, temperature, and fitness: three rules. Evolutionary Ecology Research 10:251268.

Kingsolver, J. G., G. J. Ragland, and J. G. Shlichta. 2004. Quantitative genetics of continuous reaction norms: thermal sensitivity of caterpillar growth rates. Evolution 58:15211529.

Kingsolver, J. G., H. A. Woods, L. B. Buckley, K. A. Potter, H. J. MacLean, and J. K. Higgins. 2011. Complex life cycles and the responses of insects to climate change. Integrative and Comparative Biology 51:719-732.

Knies, J. L., J. G. Kingsolver, and C. L. Burch. 2009. Hotter is better and broader: thermal sensitivity of fitness in a population of bacteriophages. American Naturalist 173:419-430.

Kochmer, J. P., and S. N. Handel. 1986. Constraints and competition in the evolution of flowering phenology. Ecological Monographs 56:303-325.

Laaksonen, T., M. Ahola, T. Eeva, R. A. Väisänen, and E. Lehikoinen. 2006. Climate change, migratory connectivity and changes in laying date and clutch size of the pied flycatcher. Oikos 114:277-290.

Lowe, C., I. Harvey, D. Thompson, and P. Watts. 2008. Strong genetic divergence indicates that congeneric damselflies Coenagrion puella and C. pulchellum (Odonata: Zygoptera: Coenagrionidae) do not hybridise. Hydrobiologia 605:55-63.
Lowe, C. D., I. F. Harvey, P. C. Watts, and D. J. Thompson. 2009. Reproductive timing and patterns of development for the damselfly Coenagrion puella in the field. Ecology 90:22022212.

Lynch, M., and W. Gabriel. 1987. Environmental tolerance. American Naturalist 129:283-303.

Mikolajewski, D. J., R. Stoks, J. Rolff, and G. Joop. 2008. Predators and cannibals modulate sex-specific plasticity in life-history and immune traits. Functional Ecology 22:114120.

Mironov, D. V. 2008. Parameterization of lakes in numerical weather prediction. Description of a lake model. COSMO Technical Report 11. Deutscher Wetterdienst, Offenbach am Main, Germany. http://www.cosmo-model.org/content/ model/documentation/techReports/docs/techReport11.pdf

Nicieza, A. G., and D. Alvarez. 2009. Statistical analysis of structural compensatory growth: how can we reduce the rate of false detection? Oecologia 159:27-39.

Nilsson-Örtman, V., R. Stoks, M. De Block, and F. Johansson. 2012. Generalists and specialists along a latitudinal transect: patterns of thermal adaptation in six species of damselflies. Ecology 93:1340-1352.

Nilsson-Örtman, V., R. Stoks, M. De Block, and F. Johansson. 2014. Competitive interactions modify the temperature dependence of damselfly growth rates. Ecology, in press.

Norling, U. 1984. Life history patterns in the northern expansion of dragonflies. Advances in Odonatology 2:127156.

Nussey, D. H., E. Postma, P. Gienapp, and M. E. Visser. 2005. Selection on heritable phenotypic plasticity in a wild bird population. Science 310:304-306.

Nylin, S., and K. Gotthard. 1998. Plasticity in life-history traits Annual Review of Entomology 43:63-83.

Ostrovsky, I. 1995. The parabolic pattern of animal growth: determination of equation parameters and their temperature dependencies. Freshwater Biology 33:357-371.

Park, T. 1954. Experimental studies of interspecies competition II. Temperature, humidity, and competition in two species of Tribolium. Physiological Zoology 27:177-238

Parmesan, C. 2006. Ecological and evolutionary responses to recent climate change. Annual Review of Ecology, Evolution, and Systematics 37:637-669.

Parry, G. D. 1978. Effects of growth and temperature acclimation on metabolic rate in the limpet, Cellana tramoserica (Gastropoda: Patellidae). Journal of Animal Ecology 47:351-368.

Persson, L., and A. M. De Roos. 2006. Size-structured interactions and the dynamics of aquatic systems. Polish Journal of Ecology 54:621-632.

Pierce, C. L., P. H. Crowley, and D. M. Johnson. 1985. Behavior and ecological interactions of larval Odonata. Ecology 66:1504-1512.

Pritchard, G. 1989. The roles of temperature and diapause in the life history of a temperate-zone dragonfly: Argia vivida (Odonata: Coenagrionidae). Ecological Entomology 14:99108.

Prosser, C. L. 1991. Environmental and Metabolic Animal Physiology: Comparative Animal Physiology. Wiley-Liss, New York, New York, USA.

R Development Core Team. 2008. R: a language and environment for statistical computing. R Foundation for Statistical Computing, Vienna, Austria.

Rabinowitz, D., J. K. Rapp, V. L. Sork, B. J. Rathcke, G. A. Reese, and J. C. Weaver. 1981. Phenological properties of wind- and insect-pollinated prairie plants. Ecology 62:49-56.

Régnière, J., and J. A. Logan. 2003. Animal life cycle models. Pages 237-254 in M. Schwarz, editor. Phenology: an integrative environmental science. Kluwer Academic, Dordrecht, The Netherlands.

Régnière, J., R. St-Amant, and P. Duval. 2012. Predicting insect distributions under climate change from physiological responses: spruce budworm as an example. Biological Invasions 14:1571-1586. 
Roff, D. A. 2002. Life history evolution. Sinauer Associates, Sunderland, Massachusetts, USA.

Rudolf, V. H. 2008. Impact of cannibalism on predator-prey dynamics: size-structured interactions and apparent mutualism. Ecology 89:1650-1660.

Scheiner, S. M. 1993. Genetics and evolution of phenotypic plasticity. Annual Review of Ecology and Systematics 24:3568.

Schulte, P. M., T. M. Healy, and N. A. Fangue. 2011. Thermal performance curves, phenotypic plasticity, and the time scales of temperature exposure. Integrative and Comparative Biology 51:691-702.

Schultz, E., K. Reynolds, and D. Conover. 1996. Countergradient variation in growth among newly hatched Fundulus heteroclitus: Geographic differences revealed by commonenvironment experiments. Functional Ecology 10:366-374.

Shama, L. N., M. Campero-Paz, K. Wegner, M. De Block, and R. Stoks. 2011. Latitudinal and voltinism compensation shape thermal reaction norms for growth rate. Molecular Ecology 20:2929-2941.

Sih, A., P. Crowley, M. McPeek, J. Petranka, and K. Strohmeier. 1985. Predation, competition, and prey communities: a review of field experiments. Annual Review of Ecology and Systematics 269-311.

Simmons, A., S. Uppala, D. Dee, and S. Kobayashi. 2007. ERA-Interim: New ECMWF reanalysis products from 1989 onwards. ECMWF Newsletter 110:25-35.

Somero, G. N. 2010. The physiology of climate change: how potentials for acclimatization and genetic adaptation wil determine "winners" and "losers." Journal of Experimental Biology 213:912-920.

Spence, J. R., D. H. Spence, and G. G. E. Scudder. 1980. The effects of temperature on growth and development of water strider species (Heteroptera: Gerridae) of central British Columbia and implications for species packing. Canadian Journal of Zoology 58:1813-1820.

Spitze, K. 1985. Functional response of an ambush predator: Chaoborus americanus predation on Daphnia pulex. Ecology 66:938-949.

Stillman, J. H. 2003. Acclimation capacity underlies susceptibility to climate change. Science 301:65-65.

Stoks, R., M. De Block, and M. A. McPeek. 2005. Alternative growth and energy storage responses to mortality threats in damselflies. Ecology Letters 8:1307-1316.

Strobbe, F., and R. Stoks. 2004. Life history reaction norms to time constraints in a damselfly: differential effects on size and mass. Biological Journal of the Linnean Society 83:187-196.
Temple, G. 1998. Testing hypotheses concerning the phenotypic plasticity of escape performance in fish of the family Cottidae. Journal of Experimental Biology 201:317-331.

Terblanche, J. S., and S. L. Chown. 2006. The relative contributions of developmental plasticity and adult acclimation to physiological variation in the tsetse fly, Glossina pallidipes (Diptera, Glossinidae). Journal of Experimental Biology 209:1064-1073.

Thomas, C. D., et al. 2004. Extinction risk from climate change. Nature 427:145-148.

Van Doorslaer, W., and R. Stoks. 2005. Thermal reaction norms in two Coenagrion damselfly species: contrasting embryonic and larval life-history traits. Freshwater Biology 50:1982-1990.

Van Noordwijk, M. 1978. A mark-recapture study of coexisting zygopteran populations. Odonatologica 7:353-374.

Varpe, Ø., C. Jørgensen, G. A. Tarling, and Ø. Fiksen. 2007. Early is better: seasonal egg fitness and timing of reproduction in a zooplankton life-history model. Oikos 116:13311342.

Via, S., and R. Lande. 1985. Genotype-environment interaction and the evolution of phenotypic plasticity. Evolution 39:505522 .

Waringer, J. A., and U. H. Humpesch. 1984. Embryonic development, larval growth and life cycle of Coenagrion puella (Odonata: Zygoptera) from an Austrian pond. Freshwater Biology 14:385-399.

Wilson, R. S., and C. E. Franklin. 2002. Testing the beneficial acclimation hypothesis. Trends in Ecology and Evolution 17:66-70.

Wilson, R. S., R. S. James, and I. A. Johnston. 2000. Thermal acclimation of locomotor performance in tadpoles and adults of the aquatic frog Xenopus laevis. Journal of Comparative Physiology B 170:117-124.

Wolda, H. 1988. Insect seasonality: why? Annual Review of Ecology and Systematics 19:1-18.

Yang, L. H., and V. H. W. Rudolf. 2009. Phenology, ontogeny and the effects of climate change on the timing of species interactions. Ecology Letters 13:1-10.

Zera, A. J., and L. G. Harshman. 2001. The physiology of life history trade-offs in animals. Annual Review of Ecology and Systematics 32:95-126.

Zhou, X., X. Liu, L. L. Wallace, and Y. Luo. 2007. Photosynthetic and respiratory acclimation to experimental warming for four species in a tallgrass prairie ecosystem. Journal of Integrative Plant Biology 49:270-281.

\section{Supplemental Material}

\section{Appendix A}

Expanded explanation of the calculations of size-corrected growth rates (Ecological Archives M083-016-A1).

\section{Appendix B}

Phenological data used to simulate larval hatching dates (Ecological Archives M083-016-A2).

\section{Appendix C}

Results from species-specific ANOVAs (Ecological Archives M083-016-A3).

\section{Supplement}

Growth rate data and $\mathrm{R}$ code for analyzing ontogenetic performance shifts, and $\mathrm{R}$ code illustrating the larval life cycle simulations (Ecological Archives M083-016-S1).

\section{Data Availability}

Data associated with this paper have been deposited in Dryad: http://dx.doi.org/10.5061/dryad.1q389 